IZA DP No. 7337

Can Microinsurance Help Prevent Child Labor? An Impact Evaluation from Pakistan

Andreas Landmann

Markus Frölich

April 2013 


\title{
Can Microinsurance Help Prevent Child Labor? An Impact Evaluation from Pakistan
}

\author{
Andreas Landmann \\ University of Mannheim \\ Markus Frölich \\ University of Mannheim, \\ IZA and ZEW
}

Discussion Paper No. 7337

April 2013

IZA

P.O. Box 7240

53072 Bonn

Germany

Phone: +49-228-3894-0

Fax: +49-228-3894-180

E-mail: iza@iza.org

\begin{abstract}
Any opinions expressed here are those of the author(s) and not those of IZA. Research published in this series may include views on policy, but the institute itself takes no institutional policy positions. The IZA research network is committed to the IZA Guiding Principles of Research Integrity.

The Institute for the Study of Labor (IZA) in Bonn is a local and virtual international research center and a place of communication between science, politics and business. IZA is an independent nonprofit organization supported by Deutsche Post Foundation. The center is associated with the University of Bonn and offers a stimulating research environment through its international network, workshops and conferences, data service, project support, research visits and doctoral program. IZA engages in (i) original and internationally competitive research in all fields of labor economics, (ii) development of policy concepts, and (iii) dissemination of research results and concepts to the interested public.
\end{abstract}

IZA Discussion Papers often represent preliminary work and are circulated to encourage discussion. Citation of such a paper should account for its provisional character. A revised version may be available directly from the author. 
IZA Discussion Paper No. 7337

April 2013

\section{ABSTRACT}

\section{Can Microinsurance Help Prevent Child Labor? An Impact Evaluation from Pakistan}

Child labor is a common consequence of economic shocks in developing countries. We show how reducing vulnerability can affect child labor and schooling. We exploit the extension of a health and accident insurance scheme by a Pakistani microfinance institution (MFI) that was set up as a randomized controlled trial and accompanied by household panel surveys. Together with increased coverage the MFI offered assistance with claim procedures in treatment branches. Using Difference-in-difference techniques we find lower incidence of child labor and lower child labor earnings caused by the innovation. Separating the two parts of the innovation package, the effects of claim assistance are mostly insignificant, while increased insurance coverage has large effects on child labor outcomes and days missed at school. Consistent with a theoretical model we develop in this paper, the effect is largely due to an ex-ante feeling of protection as opposed to a shock-mitigation effect.

JEL Classification: $\quad$ I13, J20, J82, O12

Keywords: child labor, health insurance, Pakistan

Corresponding author:

Andreas Landmann

Department of Economics

University of Mannheim

L7 3-5

68131 Mannheim

Germany

E-mail: andreas.landmann@uni-mannheim.de 


\section{Introduction}

Poor households in developing countries are especially vulnerable to economic shocks. They often have limited access to savings, credit and tangible assets. As a consequence, households might have to sell productive assets important for long-term income generation, reduce consumption below critical values, take children out of school to save school fees, or send children to work as an additional income source. The economic literature (see Edmonds (2008) for an excellent review) confirms that economic shocks are an important determinant of child labor for low-income households (e.g. Beegle, Dehejia, and Gatti 2006; Duryea, Lam, and Levison 2007). At the same time many studies show substantial negative side-effects associated with child labor, such as lower human capital accumulation (e.g. Heady 2003; Rosati and Rossi 2003; Gunnarsson, Orazem, and Sánchez 2006), lower wages in adult life (Emerson and Souza 2011) and potentially even negative long-term health outcomes (Kassouf, McKee, and Mossialos 2001).

Insurance, on the other hand, is supposed to decrease vulnerability to shocks by smoothing its economic consequences. It is therefore straightforward to think about microinsurance as a potential tool to fight child labor. Given the importance of breaking the intergenerational poverty trap, this is a highly interesting topic. Surprisingly, there is no rigorous impact evaluation studying the effect of microinsurance on child labor outcomes up to now. To the best of our knowledge, there is only one working paper comparing individuals without microcredit, microcredit clients and microcredit clients who are covered by additional insurance regarding their child labor outcomes (Chakrabarty 2012). In contrast to our study, however, his study potentially suffers from selection bias and limited sample size. ${ }^{1}$ Assessments so far have mainly focused on the impact of insurance on financial protection and access to medical services in the case of health insurance (Wagstaff 2010; Wagstaff et al. 2009; Dror, Koren, and Steinberg 2006; Dekker and Wilms 2010; Jütting 2004). Some other work has been done on agricultural investment decisions with insurance (Giné and Yang 2009) and crowding out effects on informal risk-sharing (Landmann, Vollan, and Frölich 2012). The effect of microinsurance on child labor remains an open question, though.

This paper provides evidence on the effects of insurance on child labor. We exploit the extension of an accident and health insurance scheme offered by the National Rural Support Program (NRSP), a large MFI in Pakistan. It is a mandatory insurance for all clients, their spouses and their children below 18 years. In 2009, the program was extended to include

\footnotetext{
${ }^{1}$ Chakrabarty (2012) finds that micro life and health insurance in combination with credit can reduce child labor for poor households. Unfortunately, the author cannot make use of exogenous variation in insurance coverage; the data does not have a panel dimension and the sample size is very small.
} 
supplementary household members (adult children of the client and other household members) on a voluntary basis. In addition, clients were assisted with claim procedures. This package of two innovations was implemented as a randomized controlled trial (RCT) in nine out of thirteen branch offices in the research area. The large panel data set with one baseline and four follow-up surveys allows the identification of treatment effects using difference-indifference techniques. We thus do not rely solely on the randomized design, but we are furthermore able to control for small-sample imbalances in pre-treatment covariates. We are able to disentangle the effect of the two innovation components (assistance with claims, extended coverage of household members) by estimating treatment effects for those households consisting only of individuals with mandatory insurance. Those should not be affected by the voluntary extension of coverage, but only by the assistance with claims. We contrast the effects for 'mandatory households' with estimates for households including voluntary members to obtain an estimate of the coverage effect, using triple difference techniques.

We find robust evidence for decreased child labor outcomes as a result of the innovation package. There is especially strong evidence for households to rely less on child labor earnings and to reduce hazardous occupations. Effects tend to be larger for boys, which is not surprising as they are most affected by child labor in our sample. When separating the claim assistance effects from the effects of increased coverage of households, the assistance effects are mixed and insignificant, while increased coverage clearly decreases child labor incidence, hours worked and days missed at school. These latter effects are so large that they cannot be explained by shock mitigation only. In fact, even those households never having faced a shock, or experienced an insurance payout, display similar effects. We therefore conclude that insurance coverage leads to higher perceived protection and makes parents more confident to leave children out of work and instead make them visit school more regularly.

The remainder of the article proceeds as follows. In Section II we provide background information, details on the health insurance innovation and possible effect channels, including a formal model on dynamic responses of households to changes in risk via insurance. Section III describes data collection and the resulting panel dataset. We present empirical results in Section IV and conclude in Section V. Supplementary results and descriptions are given in the appendix. 


\section{The innovation and its background}

Pakistan is a poor country: $22.3 \%$ of the population live below the poverty line of $\$ 1.25$ US per day and another $20.5 \%$ are classified as vulnerable (World Bank 2012, 19). According to the Pakistan Ministry of Health $(2009,6)$ public health expenditures are about $0.6 \%$ of GDP which is much lower than in comparable countries, and $75 \%$ of health expenditures are paid by patients out of pocket. The quality of health service providers corresponds to this low level of public health spending. While some private companies and insurers have contracts with hospitals or run their own hospitals (with varying quality), the options for the poor are limited. There are public health facilities that are supposed to be for free, but they often offer poor quality and many elements such as drugs must be paid privately as they are not covered. ${ }^{2}$ The Pakistan Ministry of Health (2009, 5-6) describes the situation for low-income households as follows:

"Poor are not benefiting from the health system whereas they bear major burden of diseases. Expanded infrastructure is poorly located, inadequately equipped and maintained resulting in inadequate coverage and access to essential basic services. Private health sector continues to expand unregulated mainly in urban areas. Factors contributing to inadequate performance of health sector are deep rooted including weak management and governance, partially functional logistics and supply systems; poorly motivated and inadequately compensated staff, lack of adequate supportive supervision, lack of evidence based planning and decision making, low levels of public sector expenditures and its inequitable distribution."

Due to the limited capacity and availability of public providers patients in some situations are forced to seek expensive private medical care. This makes health shocks a substantial economic risk for poor households. Consequently, illness and health are ranked as the top priority by potential microinsurance clients when it comes to unpredictable risk events in Pakistan (World Bank 2012, 28). Moreover, in this country with a majority of informal employment contracts there is no universal health insurance system. Instead, several arrangements coexist at a time. Social security (for police officers, soldiers, civil servants,

\footnotetext{
2 This information was gathered through multiple country-specific reports (Asian Development Bank 2004; Asian Development Bank 2005; Qamar et al. 2007). They describe the status of the Pakistani health system prior to the innovation that took place in 2009.
} 
etc.) only covers a tiny part of the population. ${ }^{3}$ There are various alternative health insurance schemes on the provincial level or offered by a multitude of private insurers; however, they are often packaged with other insurance, restricted to formal sector corporate clients and have no national outreach (World Bank 2012, 11). In any case, only $1.9 \%$ of households are estimated to use any kind of formal insurance product (World Bank 2012, 21), and the most vulnerable households are generally not the target group. Only microfinance institutions currently provide insurance for the low-income population, but here mainly schemes combining credit with life insurance are prevalent. According to the World Bank $(2012,50)$, only the NRSP is offering health microinsurance with significant outreach.

NRSP is a Pakistani non-profit organization committed to support poor and vulnerable households all over the country. It is part of the Rural Support Programs Network (RSPN) consisting of 12 rural support programs that are all active in distinct regions of Pakistan. NRSP is the largest of these support programs and serves more than two million households by offering different microfinance services (mainly credit) and client training. ${ }^{4}$ Figure 1 shows the geographic activity of NRSP within Pakistan.

Figure 1: Geographic activity of NRSP within Pakistan

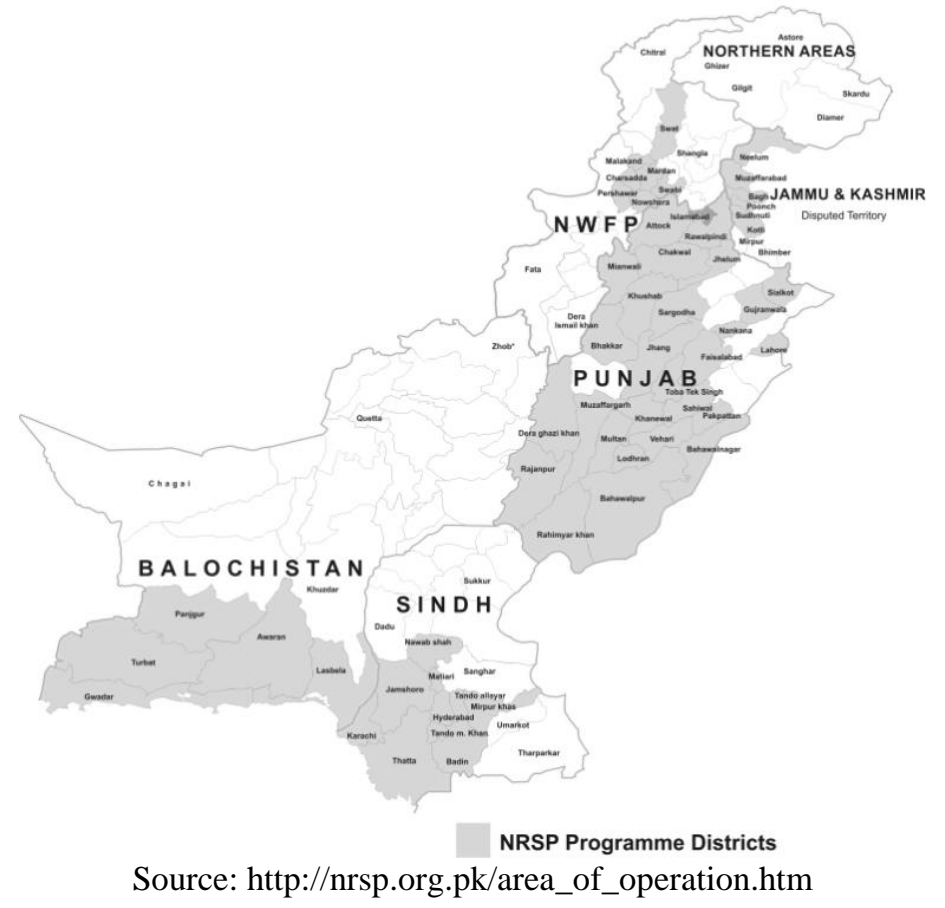

- NRSP's microinsurance innovation -

\footnotetext{
${ }^{3}$ (Asian Development Bank 2005, 2) estimates that "...less than 3\% of the total employed labor force" are covered under this formal scheme.

${ }^{4}$ See Rural Support Programs Network (2012) for more detailed information.
} 
Given the need to cover health shocks of poor households, NRSP in 2005 started to bundle health insurance to their microcredit product. Before the start of the research project, the insurance was built into the credit and was mandatory for loan clients, for their spouses and all children of the client below 18 years. ${ }^{5}$ The product covers hospital stays of more than 24 hours with a cost ceiling of 15,000 rupees (approximately 175\$ US). Covered expenses range from room charges, doctor's visits, drugs, operations, and pregnancy care to transportation costs. Also accidents leading to death or permanent disability are covered up to 15,000 rupees. Costs of hospitalization are reimbursed after contacting the MFI field officer and submitting bills along with other relevant documents. Similarly, claims after death or disability can be submitted to the MFI field officer. NRSP aims at settling all claims within 15 days. ${ }^{6}$ However, it seems that not all clients and credit officers were aware of the new product, resulting in very low claim ratios (World Bank 2012, 50; Qamar et al. 2007). In an effort to increase the social impact of its activities, NRSP in 2008 conducted a diagnostic survey in the area of Hyderabad. In this district in the south of Pakistan (Sindh province) an estimated $9.3 \%$ of all households are organized through NRSP according to Rural Support Programs Network (2012). The survey indicated high prevalence of child labor especially in the hazardous glass bangle industry and still a high vulnerability to health costs, mostly caused by accident, surgery or illness.

Responding to the vulnerability of their clients, NRSP in 2009 introduced two components additional to the mandatory insurance as part of an experiment. ${ }^{7}$ In randomly selected treatment branch offices only, additional household members (adult children of the client and other minor or adult household members) were offered a voluntary insurance for a premium of 100 rupees (approximately $1 \$$ US) per adult and year. ${ }^{8}$ Second, clients were visited monthly and asked whether they had incurred any medical costs and whether they needed assistance with claims. With increased coverage of individuals and easier filing of claims NRSP deliberately targeted child labor through a better protection of poor households. ${ }^{9}$

\footnotetext{
${ }^{5}$ The insurance product gradually changed over time. It initially covered loan clients and their spouses and was expanded in 2009 (i.e. before the baseline data used in this paper was collected) to include minor children. Also other details changed, but the basic design is what we describe in the following. For a detailed description of early product characteristics and developments we refer to Qamar et al. (2007).

${ }^{6}$ Appendix E provides a more detailed description of the insurance package and reimbursement practices.

${ }^{7}$ The experimental introduction of the innovation was financially and methodologically supported by the ILO Social Finance Program's "Microfinance for Decent Work (MF4DW)" project.

${ }^{8}$ The average monthly per capita income in our sample is around 3000 rupees (\$30-35 US) (see Table 3).

${ }^{9}$ Consequently, questions about child labor and schooling formed the core of the household questionnaire. The other sections of the questionnaire were very short to avoid annoying clients with long and repetitive surveys and to reduce administrative effort.
} 
These two components were introduced in the treatment, but not in the control branches. The clients in the control branches were not aware of the treatment. Before the modifications of the insurance were introduced, household baseline data was collected in all treatment and control branches at the same time. The geographic distribution of branches is shown in Figure 2.

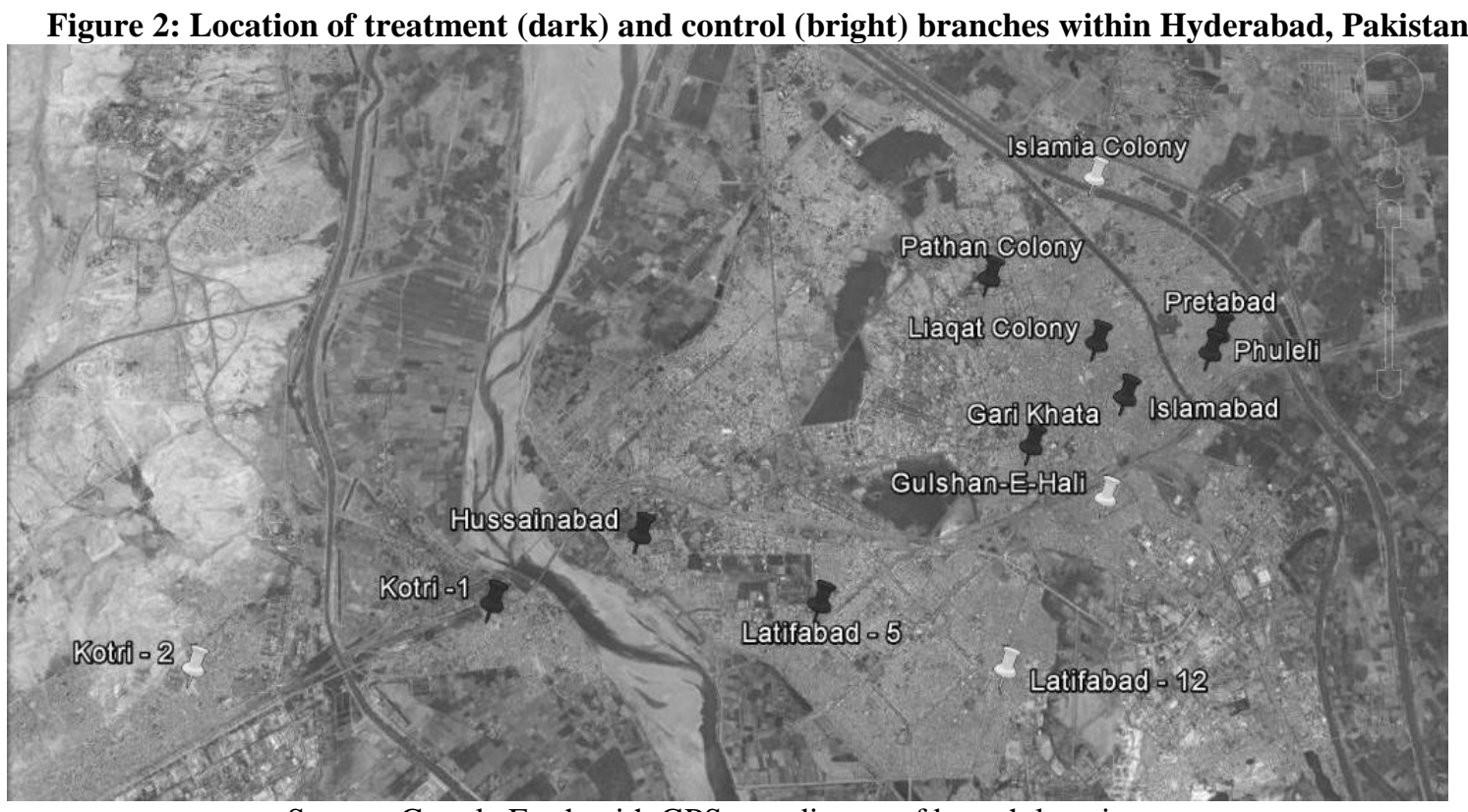

Source: Google Earth with GPS coordinates of branch locations.

The sample consists of all clients of the 13 test branch offices whose credit appraisals were conducted in September/October 2009. Thus, the complete client cohort of two months and their households are included in the study: 777 households in four control and 1320 in nine treatment branches. (The exact numbers per branch are given in Appendix D.) All households were interviewed prior to the innovation. This baseline survey took place in September and October 2009. Four follow-up surveys were then conducted every six months: March/April 2010, October/November 2010, May/June 2011, October/November 2011. The attrition rate shown in Table 1 is between $0.4 \%$ and $3.8 \%$ for each wave, and similar in treatment versus control branches. In the follow-up surveys after 12, 18 and 24 months there are a few households 'dropping back in'. Differences in attrition in the final follow up after 24 months are not significant (4.8\% in control versus $6.4 \%$ in treatment branches). There is also no evidence for differential non-response: a two-sample proportion test of the hypothesis that the fraction of households answering all survey waves are the same (92.5\% in control versus 91.4\% in treatment branches) was not rejected. Within household compositions likewise are unaffected by the innovation: We checked for treatment effects on household size, number of 
adults and number of children in different age categories. None of the regressions resulted in any significant differences.

Table 1: Attrition across waves, control versus treatment branches

\begin{tabular}{l|c|ccc|ccc}
\hline \hline & All & \multicolumn{4}{|c|}{ Control branches } & \multicolumn{3}{c}{ Treatment branches } \\
\hline & $\begin{array}{c}\text { House } \\
\text { holds }\end{array}$ & $\begin{array}{c}\text { Househ } \\
\text { olds }\end{array}$ & $\begin{array}{c}\text { Drop- } \\
\text { outs }\end{array}$ & $\begin{array}{c}\text { Drop- } \\
\text { ins }\end{array}$ & $\begin{array}{c}\text { House } \\
\text { holds }\end{array}$ & $\begin{array}{c}\text { Drop- } \\
\text { outs }\end{array}$ & $\begin{array}{c}\text { Drop- } \\
\text { ins }\end{array}$ \\
\hline Baseline & 2097 & 777 & - & - & 1320 & - & - \\
\hline $\begin{array}{l}\text { Follow up } \\
\text { after }\end{array}$ & & & & & & & \\
6 months & 2083 & 774 & $3(0.4 \%)$ & - & 1309 & $11(0.8 \%)$ & - \\
12 months & 2051 & 755 & $19(2.5 \%)$ & 0 & 1296 & $15(1.2 \%)$ & $2(18.2 \%)$ \\
18 months & 2003 & 745 & $18(2.4 \%)$ & $8(36.4 \%)$ & 1258 & $42(3.2 \%)$ & $4(16.7 \%)$ \\
24 months & 1975 & 740 & $19(2.6 \%)$ & $14(43.8 \%)$ & 1235 & $48(3.8 \%)$ & $25(40.3 \%)$ \\
\hline \hline
\end{tabular}

Note: Percentages in brackets indicate the fraction of the previous wave's observations (drop-outs) or of the previous wave's missings (drop-ins), respectively.

As stated above, the innovation consisted of two elements. We will make use of the family structure information to disentangle the effects of these two components: Families without additional household members (i.e. without adult children or other adult dependents) could not extend their coverage and were affected only by the technical assistance. Since the family structure information is also available for the control villages, we can use a type of triple difference approach to control for direct effects of the family structure.

\section{- Uptake of the innovation -}

In the following, we will describe coverage rates and uptake decisions of the innovation. Note that the sample (further described in Section III) consists of all clients of the 13 branch offices in Hyderabad whose credit appraisals are conducted in September/October 2009. They take up their loans after the baseline is conducted. Figure 3(a) shows self-assessed insurance coverage of clients across waves, where each client represents a household. Note that there are many clients who had NRSP loans already before which explains the positive coverage at baseline. We further see that there is also a positive coverage at baseline (about 50\%) in the control group. Note that the control group has insurance coverage of the nuclear family but does not receive the two innovation components, i.e. the help with claims and the extended coverage of other household members.

After the baseline all clients have a loan and $100 \%$ of clients are covered by mandatory insurance. Afterwards, coverage rates decrease due to clients repaying their loans. (After loan repayment insurance cannot be extended unless a new loan is taken.) The 
coverage rates are very similar in treatment and control branches, except for 12 months after the baseline. (The difference in month 12 is, in fact, only driven by a single control branch. Without that control branch, there would be virtually no differences. $)^{10}$

While we see little difference between treated and control group in Figure 3(a) with respect to the insurance status of the client (usually the household head or the spouse), larger differences are visible in Figure 3(b) with respect to the number of individuals in a household insured: Only the households in the treatment branches had the option to voluntarily insure those additional household members who were not mandatorily insured. Figure 3(b) thus shows insurance coverage rates at the individual level. Take-up is substantially higher in treatment than in control branches from 6 months until 18 months after the baseline. This is the result of considerable voluntary take up in the treatment branches, which is examined in Figure 3(c). There we show the number of household members who are voluntarily insured. Around $70 \%$ of those without mandatory insurance are covered in the treatment areas. The figure gradually decreases to about $50 \%$ at 18 months. In the control branches, these figures are zero since voluntary insurance of additional household members was not offered there. ${ }^{11}$

Figure 3: Insurance coverage in treatment and control branches

(a) $\%$ of clients/households

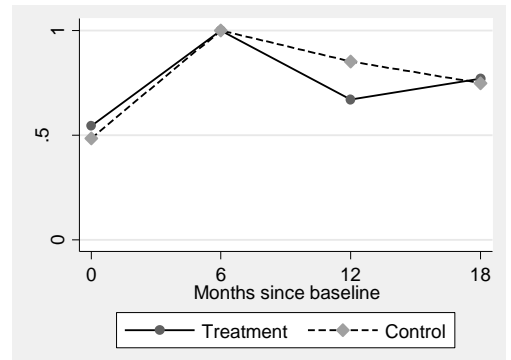

(b) \% of individuals

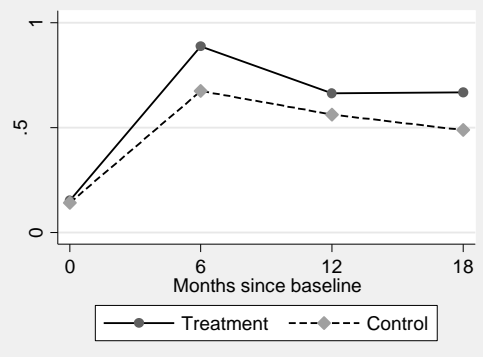

(c) \% of not mandatorily insured

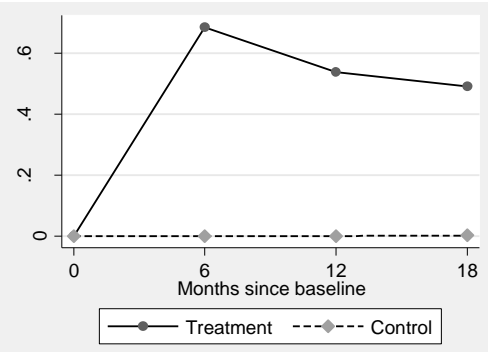

Note: Insurance coverage is self-assessed (cross-checked with MFI's information system in follow-up surveys)

The (self-assessed) take-up rates for all household members illustrated in Figure 3(b) are also shown in Table 2. Besides comparing coverage in treatment versus control branches (column 1), we also separate individuals into two categories: those with mandatory insurance (client, spouse or child $<18$ ) and those eligible for voluntary insurance (non-nuclear family or child $\geq 18$ ). Since information on family structure was collected also in the control villages, we can define these potentially eligible groups in the same way in treatment and control villages. (I.e. in Table 2 we define the group "eligible for voluntary insurance" in the control branches

\footnotetext{
${ }^{10}$ There is one of the four control branches with $100 \%$ clients having a loan and consequently insurance. Without this branch, rates would be very similar at 12 months as well.

${ }^{11}$ Note that due to data problems the insurance coverage information is not available for month 24 . In the last survey wave at month 24 , insurance coverage was no longer cross-checked with the register data and reliable information on individual insurance coverage is missing.
} 
as those individuals who would have had access to voluntary insurance if they had lived in a treatment area.)

At baseline children were not yet covered. Also, not all clients were yet aware of the coverage, so there the variable was measured with error. Nevertheless, the baseline values are very similar between treatment and control branches. After the baseline nearly all individuals with mandatory insurance (1a) also report coverage. Consistent with the randomized control design, additional voluntary insurance (1b) is taken up only in treatment branches. While virtually none in the control areas are voluntarily insured (as they had not been offered this option), nearly $70 \%$ in the treatment areas are voluntarily insured after 6 months. This number declines to about $50 \%$ until month 18 , partly also because of early repayment of loans which makes them no longer eligible.

Table 2: Insurance take-up (percent of household members), by control vs. treatment branches

\begin{tabular}{c|cc|cc|cc}
\hline \hline & \multicolumn{2}{|c|}{$\begin{array}{c}(1) \\
\text { All household } \\
\text { members }\end{array}$} & \multicolumn{2}{c|}{$\begin{array}{c}\text { (1a) } \\
\text { Mandatory } \\
\text { insurance }\end{array}$} & \multicolumn{2}{|c}{$\begin{array}{c}\text { (1b) } \\
\text { Eligible for voluntary } \\
\text { insurance** }\end{array}$} \\
\hline & Control & Treated & Control & Treated & Control & Treated \\
\hline Baseline $^{\mathrm{a}}$ & $14.1 \%$ & $15.3 \%$ & $20.6 \%$ & $22.3 \%$ & $0.0 \%$ & $0.0 \%$ \\
$\mathrm{~N}$ & 4,742 & 8,182 & 3,250 & 5,594 & 1,492 & 2,588 \\
6 months & $67.5 \%$ & $88.6 \%$ & $99.2 \%$ & $99.4 \%$ & $0.0 \%$ & $68.5 \%$ \\
$\mathrm{~N}$ & 4,781 & 8,051 & 3,252 & 5,238 & 1,529 & 2,813 \\
12 months & $56.2 \%$ & $66.3 \%$ & $84.5 \%$ & $73.1 \%$ & $0.0 \%$ & $53.9 \%$ \\
$\mathrm{~N}$ & 4,666 & 7,926 & 3,105 & 5,125 & 1,561 & 2,801 \\
18 months & $48.8 \%$ & $66.7 \%$ & $74.3 \%$ & $77.4 \%$ & $0.2 \%$ & $49.0 \%$ \\
$\mathrm{~N}$ & 4,592 & 7,809 & 3,014 & 4,877 & 1,578 & 2,932 \\
\hline \hline
\end{tabular}

Notes:

* Client/spouse/child<18 (nuclear family),

** Non-nuclear family or child $\geq 18$,

${ }^{\text {a }}$ At baseline individuals were not always fully aware of their coverage.

\section{- Definition of child labor -}

In our empirical analysis we measure child labor in various ways. Our main specification follows the ILO definition of child labor, but our main empirical results are robust to alternative definitions. The definition of child labor is sketched in Figure 4. It is mainly based on the ILO Convention C138 from 1973. ${ }^{12}$ According to the convention, child labor occurs if different conditions are met. First, all children working in hazardous occupations are automatically classified as child laborers. In our case these are mainly jobs in the dangerous

\footnotetext{
${ }^{12}$ Edmonds (2008) describes the convention in detail in his terminology section.
} 
production of glass bangles. But also welding and mechanics work belong to the hazardous occupations. If the occupation is in a non-hazardous occupation, child labor depends on age and hours worked. Young children below 12 years who work more than one hour per week, children between 12 and 13 who work more than 14 hours per week and juveniles between 14 and 17 who work more than 43 hours are defined as child laborers. Note that in our sample only children who are 5 years or older are considered as potential child laborers.

Figure 4: Child labor definition related to ILO Convention C138 (1973)

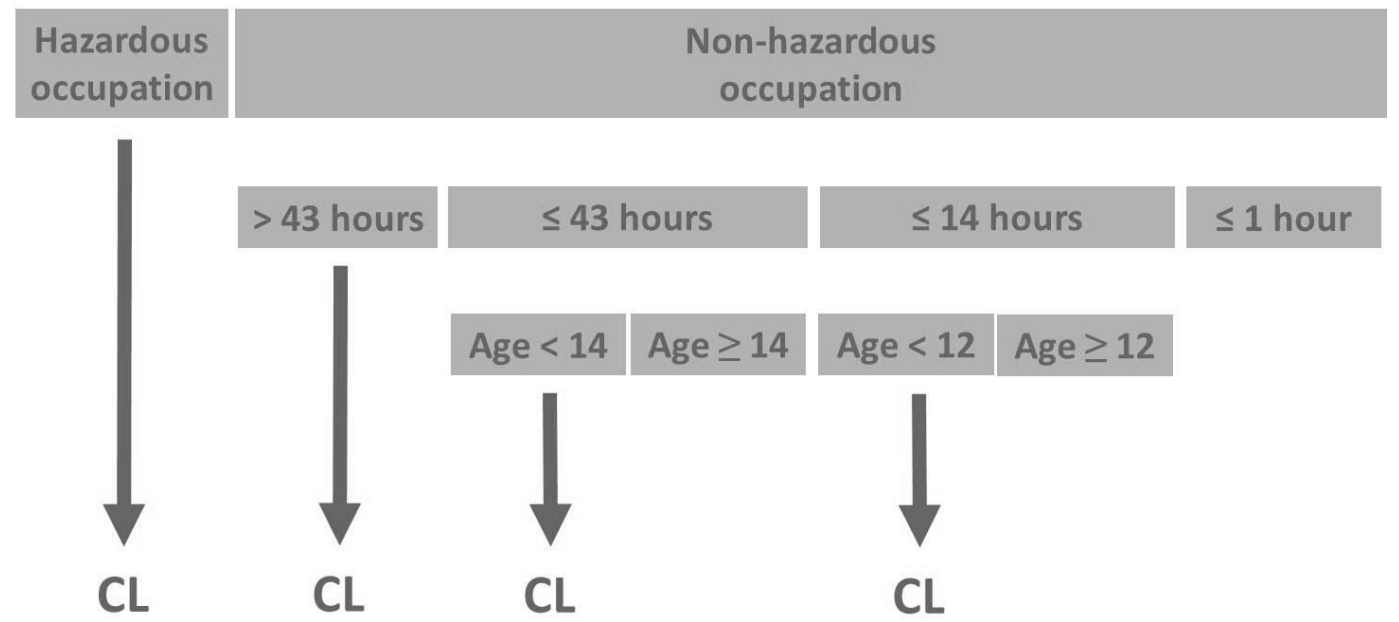

Note: $\mathrm{CL}=$ classified as child labor, hours are per week.

Of course this definition is arbitrary to some extent. Especially the age categories are important for classification as child labor. A slight transition from age 11 to 12 or from 13 to 14 might change child labor status from one to zero despite increasing hours. This is why we will control for the above age categories of children in our regressions (and why we examine various alternative definitions of child labor).

\section{- Possible effect channels -}

Health shocks may affect child labor through various channels. In the absence of insurance, health shocks will lead to health expenditures and lost labor due to sickness. This income risk affects child labor in various ways via ex-ante and ex-post effects. If a health shock happens, additional health expenses are incurred, which can push families towards poverty. There are several papers modeling economic aspects of child labor (e.g. Basu and Van 1998; Baland and Robinson 2000; Ranjan 2001) and all of them relate poverty to more child labor. Hence shocks should increase child labor, especially if households in need lack alternative coping 
mechanisms. This phenomenon is also observed empirically (Beegle, Dehejia, and Gatti 2006). Yet, there are also ex-ante effects of risk and insurance, i.e. before a shock actually happens. To the best of our knowledge only Pouliot (2006) and similarly Estevan and Baland (2007) model household risk and its consequences on child labor. However, as all previously mentioned theoretical papers, they exclusively focus on childhood condensed into a single period and the effect it creates for incomes once children become adults. Education (abstaining from child labor) for those authors is an investment that generates future budget according to a human capital production function. The efficient decision is the child labor choice that maximizes budget over all periods. Budget shocks, for example on expenditure or parental income, should not affect child labor decisions in this setting. Consequently, Pouliot (2006) and Estevan and Baland (2007) focus on shocks affecting productivity of human capital, as those should be related to child labor.

In contrast, we are interested in within-childhood dynamics and effects of potential budget shocks such as health costs. In the absence of an adequate benchmark model, we develop a simple model, which is formally described in Appendix C. Here we discuss the basic setup and the main results. We consider two periods within childhood. In both periods, parents take a decision about the amount of child labor. They take negative consequences of child labor (such as the trade-off with school attendance and learning) into account by attaching a disutility to it. In that sense child leisure is a type of consumption for parents caring about their offspring for whatever reason. On the other hand, they profit from the income generated by child labor through consumption in each period. We use a log-shaped utility function which implies that the household is risk-averse. Households maximize expected total utility over the two periods using a discount factor. Our utility function allows for probability weighting, for example the overweighting of catastrophic health shocks. Household income is generated by adults that supply labor inelastically and potential child labor. In each period there is the risk of a health shock and the shock is observed prior to child labor and consumption choices. Households will react to shocks by increasing child labor. There are also intertemporal considerations. The higher the probability or the costs of a shock, the higher is the incentive in period one to create additional resources via child labor as a precautionary buffer stock for period two.

The effect of introducing insurance is modeled via reducing the costs of a shock. In addition, the insurance premium to be paid reduces income. It is straightforward that insurance will decrease child labor in case of a shock. However, there will be an ex-ante 
effect as well. A fair insurance for period two in our model clearly decreases child labor already in period one. This is because households need to worry less about creating precautionary savings. The effect becomes more pronounced if households are poorer and if they overweight the shock probability.

There is an even stronger case of an ex-ante effect, though. If households buy insurance and have no shock they will have to pay premiums without profiting from the scheme. In our data this would be households that buy insurance, but have no shock or payout. In model terms, they buy insurance for both periods, but observe no shock in the first period. The result of the model is that if households are sufficiently poor or overweight shock probabilities enough, they will still reduce child labor in period one relative to the noinsurance case. This is because the effect of uncertainty in period two would be so large that the positive insurance effect outweighs the negative budget effect.

An additional aspect outside the model is that child labor can be seen as a tool to diversify labor market risk in a volatile economic environment. This idea relates to the literature on portfolio choices with different degree of risk exposure. In the area of agriculture high consumption risk seems to deter poor farmers from investing into more profitable but risky activities (Rosenzweig and Binswanger 1993; Dercon and Christiaensen 2011). In our case, if households are afraid of health events they might reduce risk in other domains, for example by diversifying labor market activities (including using child labor). Insurance creates a more secure environment in which households feel more comfortable to abstain from sending their children to work.

\section{The data}

Household data was collected by MFI credit officers who received special training on the questionnaire. The advantage of this approach is that the field staff knows households very well and that this way of data collection is very cost-effective. The disadvantage is that there might be stronger interviewer effects, for example due to respondents giving more 'socially desired' answers. Yet, any systematic bias should show up in both treatment and control branches, and should not affect our treatment effect estimates. Additional variation created by interviewers on the branch level will be accounted for in our regressions. 
In Table 3 we provide information on the distribution of household characteristics across treatment and control branches before the innovation was introduced. These comparisons comprise all covariates that are also used as control variables in the regression analysis. Additional household level variables are presented in Table 4. Table 5 describes the most important child level characteristics between treatment and control branches. These comparisons help to justify whether treatment and control branches are indeed comparable. We use a test for equality of means that accounts for the branch as the level of randomization. $^{13}$

Table 3: Descriptive statistics of households at baseline, by control vs. treatment branch

\begin{tabular}{|c|c|c|c|c|c|c|}
\hline & \multicolumn{2}{|c|}{$\begin{array}{l}\text { Control } \\
\text { branches }\end{array}$} & \multicolumn{2}{|c|}{ Treatment branches } & \multicolumn{2}{|c|}{ All } \\
\hline & mean & std & mean & std & $\min$ & $\max$ \\
\hline Poverty score at baseline (PPI) & 31 & 9.0 & $32 *$ & 9.8 & 8 & 79 \\
\hline Spouse in household? (yes/no) & 0.8 & 0.4 & 0.8 & 0.4 & 0 & 1 \\
\hline No. of Children age $0-4$ & 0.6 & 0.9 & 0.6 & 0.9 & 0 & 5 \\
\hline No. of Children age 5-13 & 1.5 & 1.4 & 1.5 & 1.4 & 0 & 7 \\
\hline No. of Children age 14-17 & 0.8 & 0.9 & 0.9 & 1.0 & 0 & 4 \\
\hline No. of Adults & 3.6 & 1.7 & 3.5 & 1.7 & 1 & 12 \\
\hline Mean parental age & 43 & 10 & 43 & 10 & 18 & 71 \\
\hline Mean parental education (years) & 3.1 & 3.7 & 3.9** & 4.3 & 0 & 16 \\
\hline Monthly income per capita ${ }^{\text {a }}$ & 3217 & 1150 & 3140 & 1300 & 190 & 16154 \\
\hline Observations & \multicolumn{2}{|c|}{762} & \multicolumn{2}{|c|}{1293} & \multicolumn{2}{|c|}{2055} \\
\hline
\end{tabular}

Stars indicate significance of difference between control and treatment branches $(* * * \mathrm{p}<0.01, * * \mathrm{p}<0.05, *$ $\mathrm{p}<0.1$ ), test is accounting for random effects on branch level (implemented as random-effects regression on treatment dummy),

a adjusted for minor household members (factor 0.6) and excluding income from child labor, income in Pakistani rupees (1000 Rs = approx. 11\$ US).

Households in treatment branches at baseline seem to have slightly higher values in the Progress out of Poverty Index (mean PPI score 32 vs. 31) and are also significantly better educated (mean of 3.9 vs. 3.1 years of parental education), but in all other aspects there are no significant differences between treatment and control branches. In both groups around $80 \%$ of clients have a spouse in the household. The households have on average three minor and three to four adult members (mean household size 6.5). Parents (client and spouse) are on average 43 years old and households have a mean monthly per capita income of around 3200 rupees (approx. 35\$ US). Compared to the Pakistani average client, households seem to be fairly poor: According to World Bank (2012), the poverty rate for Pakistan was at $22.3 \%$ between 2010 - 2011. Even when including income from child labor, $51 \%$ of households (or $59 \%$ of individuals) in the sample report a per capita income below this poverty line (3100 rupees

\footnotetext{
${ }^{13}$ Randomizing at the branch level is different from individual randomization. One expects larger differences to remain with bigger randomization units and the test accounts for this by allowing for branch level random effects.
} 
monthly or \$1.25 US / day). There might be some measurement error in income, but the data nevertheless indicates that NRSP is successful in targeting low-income households.

Table 4: Additional descriptive statistics of households at baseline, by control vs. treatment branch

\begin{tabular}{l|cc|cc|cc}
\hline \hline & \multicolumn{2}{|c|}{$\begin{array}{c}\text { Control } \\
\text { branches }\end{array}$} & \multicolumn{2}{c|}{$\begin{array}{c}\text { Treatment } \\
\text { branches }\end{array}$} & \multicolumn{2}{c}{ All } \\
& mean & std & mean & std & min & max \\
\hline Monthly expenses: Total & 13963 & 4725 & 12705 & 4714 & 3657 & 40780 \\
Monthly expenses: Children & 292 & 381 & 302 & 422 & 0 & 3500 \\
Monthly expenses: Books & 259 & 411 & 200 & 306 & 0 & 3000 \\
Monthly expenses: Outpatient & 501 & 559 & 380 & 435 & 0 & 4500 \\
Monthly expenses: Hospital & 107 & 478 & 59 & 365 & 0 & 10000 \\
Credit with NRSP before? (yes/no) & 0.73 & 0.45 & 0.77 & 0.42 & 0 & 1 \\
Credit amount & 16133 & 4387 & 15723 & 4916 & 5000 & 30000 \\
Difficulties repaying loan? (yes/no) & .01 & .11 & .02 & .15 & 0 & 1 \\
\hline \multicolumn{1}{c|}{ Observations } & \multicolumn{7}{|c|}{772} & \multicolumn{2}{c|}{1320} & \multicolumn{2}{c|}{2092} \\
\hline \hline
\end{tabular}

Stars indicate significance of difference between control and treatment branches $(* * * \mathrm{p}<0.01, * * \mathrm{p}<0.05, *$ $\mathrm{p}<0.1$ ), test is accounting for random effects on branch level (implemented as random-effects regression on treatment dummy), monetary units in Pakistani rupees (1000 Rs = approx. 11\$ US).

Table 4 shows average household expenditure for several categories and some credit related characteristics. Children-specific expenditures (e.g. school fees) and books together account for $4 \%$ of total expenses. Outpatient plus hospital costs make up for a similar amount. Three quarters of clients already have experience with NRSP. They take up average loans in the order of 15,000 rupees at baseline and only very few have difficulties repaying their loan. While there is some variation in numbers across treatment and control branches, none of the differences are significant.

The same is true for characteristics at the child level shown in Table 5. Average age, education level, child labor incidence (around 20\%), monthly earnings through child labor (290-340 rupees), hours worked per week (11-14 hours), hazardous occupations (9\%) and school attendance (68-70\%) are all similar for treated and control and none of the differences are significant. Note that the income generated through child labor corresponds to roughly ten percent of monthly per capita income which is a non-negligible amount. 
Table 5: Descriptive statistics of children at baseline, by control vs. treatment branch

\begin{tabular}{|c|c|c|c|c|c|c|}
\hline \multirow[b]{2}{*}{ Children 5 - 17} & \multicolumn{2}{|c|}{$\begin{array}{c}\text { Control } \\
\text { branches }\end{array}$} & \multicolumn{2}{|c|}{$\begin{array}{l}\text { Treatment } \\
\text { branches }\end{array}$} & \multicolumn{2}{|c|}{ All } \\
\hline & mean & std & mean & std & $\min$ & $\max$ \\
\hline Age & 11 & 3.7 & 12 & 3.8 & 5 & 17 \\
\hline Education (years) & 3.2 & 3.3 & 3.4 & 3.3 & 0 & 14 \\
\hline Child labor? (yes/no) & 0.20 & 0.40 & 0.19 & 0.39 & 0 & 1 \\
\hline Monthly child labor earnings ${ }^{a}$ & 290 & 1038 & 342 & 1092 & 0 & 15000 \\
\hline Hours of work (weekly) & 11 & 18 & 14 & 21 & 0 & 90 \\
\hline Hazardous occupation? (yes/no) & 0.09 & 0.29 & 0.09 & 0.28 & 0 & 1 \\
\hline Observations & \multicolumn{2}{|c|}{1650} & \multicolumn{2}{|c|}{2971} & \multicolumn{2}{|c|}{4621} \\
\hline $\begin{array}{r}\text { Children 5-14 } \\
\text { School attendance }\end{array}$ & 0.68 & 0.47 & 0.70 & 0.46 & 0 & 1 \\
\hline Observations & \multicolumn{2}{|c|}{1215} & \multicolumn{2}{|c|}{2065} & \multicolumn{2}{|c|}{3280} \\
\hline $\begin{array}{l}\text { Children 5-14 } \\
\text { Monthly school days missed }\end{array}$ & 0.86 & 3.1 & 1.2 & 3.0 & 0 & 30 \\
\hline Observations & \multicolumn{2}{|c|}{583} & \multicolumn{2}{|c|}{1442} & & \\
\hline
\end{tabular}

Stars indicate significance of difference between control and treatment branches $(* * * \mathrm{p}<0.01, * * \mathrm{p}<0.05, *$ $\mathrm{p}<0.1$ ), test is accounting for random effects on branch level (implemented as random-effects regression on treatment dummy), income in Pakistani rupees (1000 Rs = approx. 11\$ US),

${ }^{a}$ only earnings that are generated by work classified as child labor.

\section{Empirical results}

The econometric methodology used is based on the cluster experimental design of the innovation. As we have seen in the previous section, treatment and control households are mostly balanced in baseline characteristics. We therefore first compare treatment to control households. Thereafter we control for covariates in order to increase precision.

In the following figure we compare the health expenses claiming behavior between treatment and control branches. One important potential effect channel for the treatment is a better protection of households in case of a shock. Insured individuals can get their hospital costs reimbursed after submitting a claim that should be settled within 15 days, as explained in Section II. In line with higher insurance coverage we would therefore expect more claims and ultimately more reimbursement for households in treatment branches. Figure 5(a) shows the percentage of households reporting an injury or hospitalization case since the last loan disbursement. Overall, a much higher percentage declares injury or hospitalization in the treatment branches. While around $6 \%$ of control households report a medical case it is two to three times as often the case for treated households, except in the final survey wave. Also the claim frequency (Figure 5(b)) is consistently about twice as high in treatment areas. Similarly, insurance payments are more frequent (Figure 5(c)). ${ }^{14}$ Unfortunately, we do not have baseline

\footnotetext{
${ }^{14}$ Simple two-sample proportion tests show significant differences 6 months after baseline in all three variables. However, some events are extremely rare and we should be careful in interpreting the differences. While 274
} 
data for injury and hospitalization, but Figure 5(a) to 5(c) are consistent with more individuals attending hospital in case of sickness if they are insured and thus do not bear the full costs of medical treatment. The higher frequencies are likely also influenced by the sensitivity and help offered by the credit officers in the treatment branches.

Figure 5: Medical incidence, insurance claim and payment ( $\%$ of households), control vs. treatment

(a) Injured or hospitalized

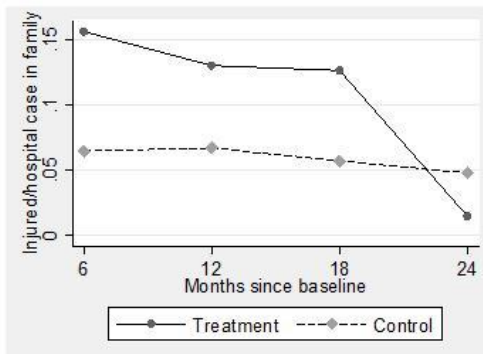

(b) Filed an insurance claim

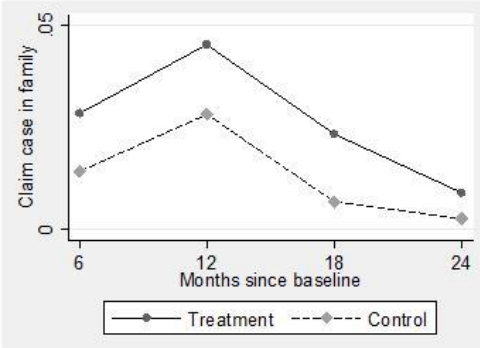

(c) Insurance paid medical costs

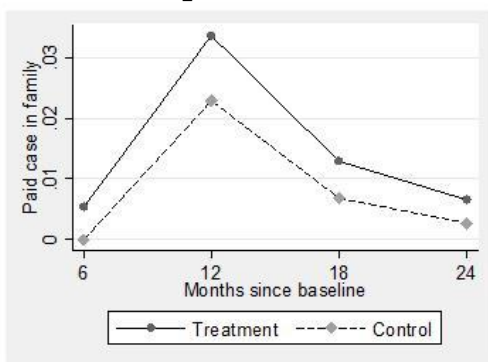

Note: There is no information available on insurance related events at baseline.

Panel (a) shows whether someone was injured or hospitalized, panel (b) shows whether an insurance claim was filed, whereas panel (c) shows whether the insurance claim was actually approved, i.e. whether medical expenses were reimbursed.

For child labor and schooling we also have baseline data. Hence for these outcome variables, the data available allows for the comparison of treatment and control branches before and after the innovation took place. For being able to interpret these as causal effects we need two assumptions: First, there should be no spillovers from the treatment into the control branches. The geographic proximity of the branches (all branches are within the urban area of Hyderabad) on the one hand increases comparability, but on the other hand facilitates spillover effects. A classical spillover effect would be the provision of additional insurance in control branches. This can fortunately be ruled out due to the rigorous control by the MFI (see Figure 3(c)). Second, outcomes in treatment and control group must follow a common trend. While this is true in expectation because of the random assignment of the treatment, the rather small number of branches entails the risk of small-sample differences in branch specific time trends. While we have little information about local branch-specific events such as changes in local economic conditions, we have relatively detailed information on the economic situation of the household and its members. We use this information to control for branch-specific trends that work through these variables.

In the following we use various panel data models where we incorporate covariates to improve precision of the estimates. As we have seen in Tables 3 to 5, the baseline

injuries or hospitalizations are reported, only 48 submitted claims and 7 claim payments can be found at $\mathrm{t}=6$ months. 
characteristics of treatment and control branches are mostly balanced, yet incorporating them in the regression may help to reduce variance. We basically follow a type of difference-indifference estimator, comparing outcomes before and after for treatment and control villages. As we have several follow up periods, we run the estimation for all periods simultaneously, while permitting that impacts may freely vary over time. (If we had only a single follow up period, our estimator would correspond to differences-in-differences.) Via random effects we account for correlation within village-wave clusters.

We estimate the econometric model:

$$
Y_{i b t}=\beta_{0}+T_{b} \lambda_{0}+\delta_{t}+T_{b} \gamma_{t}+\eta_{b t}+\varepsilon_{i b t}
$$

$Y_{i b t}$ is the outcome of interest and possibly varies over individuals $i$, branches $b$ and time $t \in\{0,6,12,18,24\} . \beta_{0}$ is the intercept and $T_{b}$ is a binary indicator whether the individual is located in a treatment or a control branch. $\lambda_{0}$ seizes baseline differences between treatment and control branches and $\delta_{t}$ measures common time trends, while $\gamma_{t}$ captures the timespecific treatment effect ( $\gamma_{0}$ is restricted to zero). Besides the classical $\varepsilon_{i b t}$ error term, which is assumed to be i.i.d., we allow for an unobserved branch-time specific error component $\eta_{b t}$, which is assumed to be uncorrelated with the treatment variable (random effect). $\eta_{b t}$ is incorporated to capture within branch-wave correlation of individual outcomes. In model (2) we also include a vector of covariates $X_{i b t}$ that may vary over individuals, branches and time:

$$
Y_{i b t}=X_{i b t} \beta+T_{b} \lambda_{0}+\delta_{t}+T_{b} \gamma_{t}+\eta_{b t}+\varepsilon_{i b t}
$$

The regression results shown later always comprise different specifications. We first show treatment effects for each wave without controlling for covariates using random effects at the branch-wave level $\left(\eta_{b t}\right)$ in specification (1). In most cases the precision of estimates is considerably lower with random effects, showing that those unobserved effects seem to be quite important. We also examined specifications with branch specific random effects only instead of branch-wave random effects. We obtained very similar and slightly more precise results. Here we only report the results for the more flexible specification with branch-wave random effects, i.e. where the branch effects are permitted to vary arbitrarily over time.

In specification (2) we control for household and individual covariates: poverty level at baseline, current monthly income per capita (excluding child labor earnings), health shocks, non-health economic shocks, death of family members as well as individual demographics. 
Note that non-child labor income could be endogenous. However, we did not find any independent treatment effect on income. Furthermore, we also examine an alternative specification in Table A2 in the appendix where we do not include income as a regressor, and obtain very similar results.

The treatment effect estimates have to be interpreted as the combined effect of technical assistance with claims (i.e. the monthly visits of credit officers assisting with claim procedures) and the offer of additional insurance coverage. Hence, we compare households who have been offered additional coverage with those who did not have this option. (I.e. we do not directly compare households who have or have not purchased extended insurance, but according to the binary treatment status of their location of residence.)

The following Table 6 shows treatment effects on child labor related variables: child labor incidence, monthly income generated through child labor, hours worked by children and work in hazardous occupations. Note that the child labor definition depends on hours worked and hazardous occupation and thus any effect on those two variables should also propagate through child labor incidence and earnings. In specification (1), i.e. without covariates, all treatment effects are negative. Effects are closer to zero 18 months after baseline, but substantial in all other waves. Despite the size of the effects, the coefficients are only statistically significant for hazardous work and monthly child labor earnings. Including control variables in specification (2) does not change coefficients much, but standard errors decrease by around one third. The individual and household covariates thus effectively reduce unexplained variation without any signs of selective treatment assignment. The relatively largest effect of the innovation is on the prevalence of hazardous occupations and income generated by child labor. ${ }^{15}$ Hazardous work and child labor income clearly decrease. The effects on the other child labor indicators are also negative, but less precisely estimated. Furthermore, effects tend to be bigger for boys than for girls.

In Table 6 we only report the coefficient on the treatment indicator. The coefficients on the other control variables are given in Table A1 in the appendix. The results of Table A1 confirm the basic intuition that economic shocks and poverty drive children into child labor and out of school.

\footnotetext{
${ }^{15}$ See Table 5 (child level characteristics at baseline) to obtain an impression for relative effect sizes. Figure A1 in the appendix shows time trends in treatment versus control branches for all variables. These reflect the results of specification (1) and provide a visual impression of effect sizes.
} 
Table 6: Treatment effects on child labor indicators

\begin{tabular}{|c|c|c|c|c|}
\hline \multirow{4}{*}{$\begin{array}{l}\text { Standard Errors } \\
\text { Controls }\end{array}$} & \multirow{4}{*}{$\begin{array}{l}(1) \\
\text { RE } \\
\text { NO } \\
\end{array}$} & \multirow{4}{*}{$\begin{array}{c}\text { (2) } \\
\\
\text { RE } \\
\text { YES } \\
\end{array}$} & \multicolumn{2}{|c|}{ Specification (2) for } \\
\hline & & & Boys & Girls \\
\hline & & & $\mathrm{RE}$ & RE \\
\hline & & & YES & YES \\
\hline & \multicolumn{4}{|c|}{$\begin{array}{c}\text { Child labor (age 5-17) - binary definition } \\
\text { according to ILO convention }\end{array}$} \\
\hline \multirow[t]{2}{*}{ Treatment Effect 6 months } & -0.039 & -0.023 & -0.067 & 0.019 \\
\hline & $(0.057)$ & $(0.041)$ & $(0.044)$ & $(0.061)$ \\
\hline \multirow[t]{2}{*}{ Treatment Effect 12 months } & -0.069 & $-0.067 *$ & $-0.098 * *$ & -0.039 \\
\hline & $(0.056)$ & $(0.040)$ & $(0.043)$ & $(0.060)$ \\
\hline \multirow[t]{2}{*}{ Treatment Effect 18 months } & -0.0040 & 0.015 & -0.037 & 0.062 \\
\hline & $(0.056)$ & $(0.040)$ & $(0.043)$ & $(0.060)$ \\
\hline \multirow[t]{2}{*}{ Treatment Effect 24 months } & -0.025 & -0.029 & $-0.10 * *$ & 0.038 \\
\hline & $(0.056)$ & $(0.040)$ & $(0.043)$ & $(0.060)$ \\
\hline \multirow[t]{2}{*}{$\mathrm{N}$} & 20531 & 20491 & 10432 & 10059 \\
\hline & \multicolumn{4}{|c|}{ Hours worked by children (age 5-17) } \\
\hline \multirow[t]{2}{*}{ Treatment Effect 6 months } & -2.42 & -1.28 & $-3.61 *$ & 0.99 \\
\hline & $(2.32)$ & $(1.76)$ & $(2.04)$ & $(2.49)$ \\
\hline \multirow[t]{2}{*}{ Treatment Effect 12 months } & -3.09 & -2.78 & $-4.91 * *$ & -0.67 \\
\hline & $(2.27)$ & $(1.72)$ & $(2.00)$ & $(2.43)$ \\
\hline \multirow[t]{2}{*}{ Treatment Effect 18 months } & -0.33 & 0.67 & -1.78 & 2.97 \\
\hline & $(2.27)$ & $(1.72)$ & $(2.00)$ & $(2.43)$ \\
\hline \multirow[t]{2}{*}{ Treatment Effect 24 months } & -1.75 & -1.53 & $-5.32 * * *$ & 2.06 \\
\hline & $(2.27)$ & $(1.72)$ & $(2.00)$ & $(2.44)$ \\
\hline \multirow[t]{2}{*}{$\mathrm{N}$} & 20527 & 20487 & 10431 & 10056 \\
\hline & \multicolumn{4}{|c|}{ Hazardous occupation (age 5-17) } \\
\hline \multirow[t]{2}{*}{ Treatment Effect 6 months } & $-0.057 *$ & $-0.053 * *$ & -0.036 & $-0.065 *$ \\
\hline & $(0.034)$ & $(0.022)$ & $(0.023)$ & $(0.034)$ \\
\hline \multirow[t]{2}{*}{ Treatment Effect 12 months } & $-0.062 *$ & $-0.061 * * *$ & $-0.061 * * *$ & $-0.058 *$ \\
\hline & $(0.034)$ & $(0.021)$ & $(0.023)$ & $(0.034)$ \\
\hline \multirow[t]{2}{*}{ Treatment Effect 18 months } & -0.030 & -0.024 & -0.018 & -0.030 \\
\hline & $(0.034)$ & $(0.021)$ & $(0.023)$ & $(0.034)$ \\
\hline \multirow[t]{2}{*}{ Treatment Effect 24 months } & -0.036 & -0.033 & $-0.046 * *$ & -0.021 \\
\hline & $(0.034)$ & $(0.021)$ & $(0.023)$ & $(0.034)$ \\
\hline \multirow[t]{2}{*}{$\mathrm{N}$} & 21216 & 20491 & 10432 & 10059 \\
\hline & \multicolumn{4}{|c|}{ Monthly earnings through child labor (age 5-17) } \\
\hline \multirow[t]{2}{*}{ Treatment Effect 6 months } & $-216 * *$ & $-162 *$ & -231 & $-107 *$ \\
\hline & $(107)$ & $(95.9)$ & $(145)$ & $(56.1)$ \\
\hline \multirow[t]{2}{*}{ Treatment Effect 12 months } & $-195 *$ & $-190 * *$ & $-272 *$ & $-110 * *$ \\
\hline & $(105)$ & $(93.8)$ & $(142)$ & $(54.9)$ \\
\hline Treatment Effect 18 months & -5.66 & 44.9 & 87.0 & -8.78 \\
\hline & $(105)$ & $(93.9)$ & $(142)$ & $(55.0)$ \\
\hline Treatment Effect 24 months & -172 & $-191 * *$ & $-377 * * *$ & -21.0 \\
\hline & $(105)$ & $(94.0)$ & (142) & $(55.2)$ \\
\hline $\mathrm{N}$ & 20531 & 20491 & 10432 & 10059 \\
\hline
\end{tabular}


The treatment effects on school attendance and school days missed per month are provided in Table 7. We find a modest but insignificant positive effect on school attendance, while the number of missed school days per month decreases (again not statistically significant).

Table 7: Treatment effects on schooling variables

\begin{tabular}{|c|c|c|c|c|}
\hline \multirow{4}{*}{$\begin{array}{l}\text { Standard Errors } \\
\text { Controls }\end{array}$} & \multirow{4}{*}{$\begin{array}{l}(1) \\
\text { RE } \\
\text { NO } \\
\end{array}$} & \multirow{4}{*}{$\begin{array}{c}(2) \\
\text { RE } \\
\text { YES } \\
\end{array}$} & \multicolumn{2}{|c|}{ Specification (2) for } \\
\hline & & & Boys & Girls \\
\hline & & & $\mathrm{RE}$ & $\mathrm{RE}$ \\
\hline & & & YES & YES \\
\hline & \multicolumn{4}{|c|}{ School attendance of children (age 5-14) } \\
\hline \multirow[t]{2}{*}{ Treatment Effect 6 months } & 0.0027 & 0.014 & 0.035 & -0.0084 \\
\hline & $(0.064)$ & $(0.029)$ & $(0.038)$ & $(0.048)$ \\
\hline \multirow[t]{2}{*}{ Treatment Effect 12 months } & 0.025 & 0.023 & 0.037 & 0.0095 \\
\hline & $(0.064)$ & $(0.028)$ & $(0.037)$ & $(0.047)$ \\
\hline \multirow[t]{2}{*}{ Treatment Effect 18 months } & 0.013 & 0.0068 & 0.019 & -0.0092 \\
\hline & $(0.064)$ & $(0.028)$ & $(0.037)$ & $(0.047)$ \\
\hline \multirow[t]{2}{*}{ Treatment Effect 24 months } & 0.014 & 0.026 & 0.025 & 0.027 \\
\hline & $(0.064)$ & $(0.029)$ & $(0.037)$ & $(0.047)$ \\
\hline \multirow[t]{2}{*}{$\mathrm{N}$} & 15444 & 14930 & 7717 & 7213 \\
\hline & \multicolumn{4}{|c|}{ Monthly school days missed by school children (age 5-14) } \\
\hline \multirow[t]{2}{*}{ Treatment Effect 6 months } & 0.19 & -0.044 & 0.033 & -0.12 \\
\hline & $(0.56)$ & $(0.41)$ & $(0.49)$ & $(0.46)$ \\
\hline \multirow[t]{2}{*}{ Treatment Effect 12 months } & -0.12 & -0.14 & 0.020 & -0.30 \\
\hline & $(0.56)$ & $(0.40)$ & $(0.48)$ & $(0.45)$ \\
\hline \multirow[t]{2}{*}{ Treatment Effect 18 months } & -0.29 & -0.27 & -0.29 & -0.25 \\
\hline & $(0.56)$ & $(0.40)$ & $(0.48)$ & $(0.45)$ \\
\hline \multirow[t]{2}{*}{ Treatment Effect 24 months } & -0.15 & -0.18 & -0.12 & -0.25 \\
\hline & $(0.56)$ & $(0.41)$ & $(0.48)$ & $(0.45)$ \\
\hline $\mathrm{N}$ & 10,545 & 10,212 & 5,149 & 5,063 \\
\hline
\end{tabular}

\section{- Disentangling the treatment effects -}

As explained in Section II, the innovation in the treatment branches consisted of two elements: (i) assistance with filing claims (i.e. frequent visits of credit officers to assist with claim procedures) and (ii) the option to voluntarily insure other household members (extended insurance coverage). In the following we will disentangle the effects of each element. We exploit a special feature of the innovation that creates an additional control group within the treatment group, allowing a type of triple difference approach. Remember that the so-called nuclear family (client, spouse and minor children) is covered by mandatory insurance. Therefore extending (voluntary) insurance coverage should have no effect on households consisting only of mandatorily insured individuals. We estimate the treatment effect for those 
households with potential voluntary members relative to those with mandatory members only. The latter hence acts as an internal control group and should capture either effects of monthly visits or deviations from the common time trend assumption. (Since we know the household structure also for the control branches, we can define these groups in all branches.) Thereby we can isolate the effect of extended coverage. We implement our strategy extending the original model as follows:

$$
Y_{i b t v}=X_{i b t} \beta_{v}+T_{b} \lambda_{0 v}+\delta_{t v}+T_{b} \gamma_{t}+V_{i} T_{b} \lambda_{t}+\eta_{b t}+\varepsilon_{i b t}
$$

where $V_{i} \in\{0,1\}$ indicates whether the household contains "non-nuclear" members. In other words, the indicator shows whether the household includes other individuals besides client, spouse or minor children. In equation (3) we permit all coefficients to vary by 'household type' v (only mandatory members vs. potential voluntary members) which incorporates the flexibility of two separate regressions, but allows a direct test of the extended coverage effect $\left(H_{0}: \lambda_{t}=0\right)$.

Table 8 shows treatment effects for 'mandatory' household types and additional effects for 'voluntary' types. The upper half of Table 8 shows the estimated treatment effects for those households who have only nuclear-family members. I.e. these households could not extend their coverage and the estimated treatment effects thus can only reflect the effects of the assistance with filing claims (via the frequent visits of the credit officers). The lower half of Table 8, on the other hand, shows the estimate on the interaction term, i.e. for those households with at least one member that did not belong to the nuclear family and thus had the option to insure voluntarily. The estimates in the lower half of the table thus show the isolated effect of the extended coverage only. (The total effect on households with voluntary members is thus the sum of the estimates in the upper and the lower half of the table.)

In the upper half of the table most effects are insignificant. Only two out of 24 coefficients are significant at the 5\% level and only at a single point in time. The other estimates are not even significant at the $10 \%$ level. On the other hand, we find many significant effects in the lower half, which all have the expected sign. We find large effects on child labor and hours worked. Effects on earnings through child labor and the incidence of hazardous occupations are significant only in the last wave, though. We also find a reduction of monthly school days missed through offering higher insurance coverage.

We examine an alternative specification in Table A3 in the appendix, where we do not include income as a regressor. The results on the coverage effect remain stable. Furthermore, the results are robust to alternative definitions of child labor. Table A4 in the appendix shows 
results for different definitions of child labor. The results for extending insurance coverage to additional household members remain very large and highly significant. In addition, we now also find several significant effects for the "nuclear family" households, i.e. for the assistance with filing claims, but their size varies substantially over time. Also, remember that different to the lower half of the table - the upper part on claim assistance might capture deviations from the common time trend assumption such that we do not want to draw strong conclusions from those estimates.

Table 8: Disentangling treatment effects on children's outcomes

\begin{tabular}{|c|c|c|c|c|c|c|}
\hline & $\begin{array}{l}\text { Child } \\
\text { labor }\end{array}$ & $\begin{array}{c}\text { Hours } \\
\text { worked }\end{array}$ & $\begin{array}{c}\text { Child } \\
\text { labor } \\
\text { earnings }\end{array}$ & $\begin{array}{l}\text { Hazardous } \\
\text { occupation }\end{array}$ & $\begin{array}{c}\text { School } \\
\text { attendance }\end{array}$ & $\begin{array}{l}\text { Days } \\
\text { missed }\end{array}$ \\
\hline TE 6 months - mandatory & 0.046 & 1.69 & -58.2 & -0.029 & -0.011 & 0.61 \\
\hline TE 12 months - mandatory & 0.019 & 1.02 & -59.5 & -0.030 & 0.012 & 0.49 \\
\hline TE 18 months - mandatory & $0.10 * *$ & $3.24 * *$ & 132 & -0.0063 & -0.014 & 0.62 \\
\hline TE 24 months - mandatory & 0.069 & 1.57 & -52.9 & 0.0066 & 0.025 & 0.64 \\
\hline$\Delta$ TE 6 months - voluntary & $-0.088 * *$ & $-3.87 * *$ & -137 & -0.029 & 0.035 & $-0.95 * * *$ \\
\hline$\Delta \mathrm{TE} 12$ months - voluntary & $-0.12 * * *$ & $-5.13 * * *$ & -170 & -0.043 & 0.019 & $-0.93 * * *$ \\
\hline$\Delta \mathrm{TE} 18$ months - voluntary & $-0.12 * * *$ & $-3.33 * *$ & -112 & -0.024 & 0.030 & $-1.33 * * *$ \\
\hline$\Delta \mathrm{TE} 24$ months - voluntary & $-0.13 * * *$ & $-4.27 * * *$ & $-188 *$ & $-0.057 * *$ & 0.0049 & $-1.24 * * *$ \\
\hline Controls & YES & YES & YES & YES & YES & YES \\
\hline $\mathrm{N}$ & 20,491 & 20,487 & 20,491 & 20,491 & 14,930 & 10,212 \\
\hline
\end{tabular}

To interpret our findings, we need to keep in mind that our estimated effects for the coverage extension are intention to treat effects (ITT). I.e. in contrast to the assistance to claims, which is provided to everyone in the treatment group, the isolated effects for coverage extension capture the option to voluntarily buy further insurance. According to Table 8, this option decreases child labor by $8.8 \%$ after 6 months on average. Note that the percentage of child laborers 6 months after baseline in treatment branches in 'voluntary' households is $21.9 \%$, thus without the innovation it would have been $30.7 \%$. These effects are substantial and could arise through various channels. We first need to discuss how many household members actually receive additional insurance cover. In the aforementioned subsample, $86 \%$ of children see an additional household member being insured in the treatment branches. Almost half of them now live in households with complete coverage. This means that offering increased coverage indeed led to substantially higher coverage. On the other hand, the nuclear family is insured anyway and the additional coverage affects only part of the household. Also, 
claim and payment experience is limited, see Figure 4. These considerations make it rather unlikely that actual payout in case of a shock saves children from being pushed into child labor. Instead ex-ante effects, such as psychological factors and expectations of parents, appear to be very important. Families might feel more protected from costs arising from a health shock to one household member and thus might rely less on their children as a source of precautionary income. This argument for ex-ante effects would be in line with our theoretical results derived in Appendix C. If vulnerability of a household already increases child labor, even without a shock being present, covering the household completely should indeed have large effects as opposed to covering only part of it, as the risk of catastrophic health spending is only eliminated with complete insurance coverage. Also, according to our model the effects of introducing insurance should be strongest for poor households. Given that more than half of all households report an income below the poverty line at baseline, we would expect such ex-ante effects in our sample.

\section{- Ex-post versus ex-ante effects -}

In Table 9 we formally assess whether most of the effect indeed exists even without the insurance paying out a claim following a shock (ex-ante effect). The idea is as follows. Some households are randomly hit by a health shock whereas others are not. Assuming that health shocks are largely exogenous (i.e. that the presence of insurance does not change the healthrisk taking behavior of individuals very much), the former households would be affected by the ex-ante and the ex-post effects, whereas the latter would only be affected by the ex-ante effect. We thus repeat the previous analyses separately for households hit by a health shock and those not hit by a shock. Unfortunately, the sample size is too small for a meaningful analysis for households with a shock, such that we can only examine the subsample without a shock. We thus compare the estimates for this subsample without a health shock (i.e. without ex-post effects) to the results for the total population of Table 8 . If the effects found in Table 8 were mostly due to ex-post effects, the treatment effect estimates should become much smaller or vanish if we only examine households without shock in the following table. On the other hand, if ex-ante effects were important, the results in the following table should be similar to those of Table 8 .

Table 9 shows the regression results in the subsample without the approximately 5\% of households that received a claim payment at some point in time. The coefficients for "voluntary" households (i.e. the pure coverage effect in the lower half of the table) have about 
the same magnitude and significance as in the full sample in Table 8. Hence, focusing only on households without shocks and thereby "blocking" the channel through claim payments does not substantially change the estimates.

In Table A5 in the appendix we consider an alternative definition of a health shock to examine the robustness of the results of Table 9. There we exclude all households that at any time reported a death or health case in the household. The results for the coverage effect are similar to Table 9. (We defer Table A5 to the appendix as we are somewhat concerned with data quality regarding this survey item since households in the treatment group report injuries more often than those in the control group.)

Table 9: Disentangling treatment effects on children's outcomes - ruling out insurance payment effects (without households with paid claims at any time)

\begin{tabular}{|c|c|c|c|c|c|c|}
\hline & $\begin{array}{l}\text { Child } \\
\text { labor }\end{array}$ & $\begin{array}{c}\text { Hours } \\
\text { worked }\end{array}$ & $\begin{array}{c}\text { Child } \\
\text { labor } \\
\text { earnings }\end{array}$ & $\begin{array}{l}\text { Hazardous } \\
\text { occupation }\end{array}$ & $\begin{array}{c}\text { School } \\
\text { attendance }\end{array}$ & $\begin{array}{l}\text { Days } \\
\text { missed }\end{array}$ \\
\hline TE 6 months - mandatory & 0.054 & 2.00 & -61.6 & -0.028 & -0.015 & 0.48 \\
\hline TE 12 months - mandatory & 0.022 & 1.14 & -54.4 & -0.030 & 0.016 & 0.31 \\
\hline TE 18 months - mandatory & $0.11 * *$ & $3.47 *$ & 140 & -0.0051 & -0.0034 & 0.56 \\
\hline TE 24 months - mandatory & 0.077 & 1.88 & -29.5 & 0.0062 & 0.031 & 0.53 \\
\hline$\Delta \mathrm{TE} 6$ months - voluntary & $-0.093 * *$ & $-3.86 * *$ & -135 & -0.034 & 0.043 & $-0.71 * *$ \\
\hline$\Delta \mathrm{TE} 12$ months - voluntary & $-0.12 * * *$ & $-5.07 * * *$ & -175 & $-0.045 *$ & 0.023 & $-0.67 * *$ \\
\hline$\Delta \mathrm{TE} 18$ months - voluntary & $-0.12 * * *$ & $-3.10 *$ & -112 & -0.025 & 0.025 & $-1.13 * * *$ \\
\hline$\Delta \mathrm{TE} 24$ months - voluntary & $-0.14 * * *$ & $-4.25 * * *$ & $-214 *$ & $-0.057 * *$ & 0.0087 & $-1.01 * * *$ \\
\hline Controls & YES & YES & YES & YES & YES & YES \\
\hline $\mathrm{N}$ & 19,575 & 19,571 & 19,575 & 19,575 & 14,201 & 9,667 \\
\hline
\end{tabular}

The results of Table 9 are in line with our theoretical model, which suggests that expectations of parents about risk might play a very large role. Being protected by insurance and thus expecting less severe shocks in the future might already reduce child labor today. This is especially true in a context where health shocks can have devastating effects. As Qamar et al. (2007, 8) state in the context of Pakistan: "A major illness of just one member of the household (especially if he/she is the primary bread earner) can throw the entire family into poverty." Hence, the fear of this type of shock and the underlying feeling of vulnerability should be very strong. A precautionary and rational response to this fear is using child labor to accumulate additional financial resources. 


\section{Conclusion}

Economic shocks play a large role for poor households. One of the undesired consequences might be that hardship forces parents to send children to work or take them out of school. This coping strategy is especially dangerous because it may harm long-term human capital accumulation or health for the next generation. Microinsurance is widely promoted as a tool to reduce vulnerability to shocks and hence potentially protects children from child labor. So far there are almost no studies assessing the effect of formal insurance on child labor and schooling outcomes, though.

It is straightforward to imagine that insurance will protect children from being pushed into child labor once medical costs arise. Yet, a change in economic uncertainty might also have effects ex ante, before a shock actually takes place. To improve our understanding of possible effect channels we formally model the relationship between economic risk and child labor input. The model shows that risk-averse households respond to high risk by using child labor as an additional precautionary income source. If households are sufficiently poor and afraid of the shock, they will react to the introduction of insurance by reducing child labor even without a shock taking place.

To estimate the actual effect of insurance we exploit a randomized controlled trial in Hyderabad, Pakistan. An innovation package consisting of (a) the extension of voluntary health insurance coverage and (b) regular visits sensitizing microcredit clients regarding claim procedures was introduced in nine treatment branches. We make use of a baseline and four follow-up survey waves to estimate time-varying treatment effects. We also account for unobserved random effects on the branch-wave level by using random effect regressions.

We find that the innovation package indeed helps to reduce child labor related outcomes. The combination of offering increased coverage and helping with claims decreases hazardous work and earnings generated through child labor.

To disentangle the effects of extended coverage and regular claim assistance visits we use the feature that certain household types are completely covered by mandatory insurance and have no possibility to extend coverage. We thereby isolate the effect of regular visits for those households with only mandatory members. These households by definition have the same coverage in treatment and control branches and can serve as an additional control group within treatment branches. Using this triple difference estimator we find that the main effect of the innovation is caused by extending insurance coverage to other household members. The extension reduces child labor incidence by around ten percent, weekly hours worked by 
children by around four and days missed at school by around one. Monthly visits alone, on the other hand, have little significant effects.

We present additional evidence suggesting that most of the coverage effect is an exante effect. This means that increasing coverage within the household already protects children, even before health shocks taking place. Based on our theoretical model we argue that with a decrease in perceived vulnerability households seem to feel more comfortable to abstain from child labor as a precautionary income source. The channel is plausible: health is considered the most important factor of risk in Pakistan and medical costs are especially devastating for the poor. The microfinance clients in our sample to a large extent are below the poverty line and can therefore be expected to react strongly to a change in vulnerability.

\section{Acknowledgements}

We gratefully acknowledge financial and logistical support from the International Labor Office (Social Finance Programme with a Microfinance for Decent Work project). We thank Esther Blanco, Boris Branisa, Dirk Engelmann, Niels Kemper, Vera Molitor, Ralf Rademacher, Susan Steiner, Pia Unte and seminar/conference participants in Mannheim (Junior Research Seminar in Empirical Economics), Twente (Microinsurance Research Conference) and Dar El Salaam ( $8^{\text {th }}$ International Microinsurance Conference) for helpful and valuable comments. Many thanks also in particular to Hillery Midkiff (ILO), Valerie Breda (ILO), Tahir Waqar (NRSP) and Torben Fischer for their support. We also acknowledge financial support from the Research Center (SFB) 884 "Political Economy of Reforms" Project B5, funded by the German Research Foundation (DFG). 


\section{References}

Asian Development Bank. 2004. Social Protection Strategy. Final Report Vol . II: Health Insurance. http://www2.adb.org/Documents/Reports/Consultant/37008PAK/vol2/37008b.pdf.

2005. Technical Assistance to the Islamic Republic of Pakistan for the Developing Social Health Insurance Project. http://www2.adb.org/Documents/TARs/PAK/tar-pak37359.pdf.

Baland, JM, and JA Robinson. 2000. “Is Child Labor Inefficient?” Journal of Political Economy 108 (4): 663-679.

Basu, Kaushik, and Pham Hoang Van. 1998. "The Economics of Child Labor." American Economic Review 289 (4): 84-91.

Beegle, Kathleen, Rajeev H. Dehejia, and Roberta Gatti. 2006. "Child Labor and Agricultural Shocks.” Journal of Development Economics 81 (1): 80-96.

Chakrabarty, Sayan. 2012. "Does Micro Credit Increase Child Labour in Absence of Micro Insurance?” Microinsurance Innovation Facility Research Paper 12.

Dekker, Marleen, and Annegien Wilms. 2010. "Health Insurance and Other Risk-Coping Strategies in Uganda: The Case of Microcare Insurance Ltd.” World Development 38 (3): 369-378.

Dercon, Stefan, and Luc Christiaensen. 2011. "Consumption Risk, Technology Adoption and Poverty Traps: Evidence from Ethiopia.” Journal of Development Economics 96 (2): 159-173.

Dror, David Mark, Ruth Koren, and David Mark Steinberg. 2006. “The Impact of Filipino Micro Health-insurance Units on Income-related Equality of Access to Healthcare." Health Policy 77 (3): 304-17.

Duryea, Suzanne, David Lam, and Deborah Levison. 2007. "Effects of Economic Shocks on Children's Employment and Schooling in Brazil." Journal of Development Economics 84 (1): 188-214.

Edmonds, Eric V. 2008. “Child Labor.” In Handbook of Development Economics Volume 4, ed. T P Schultz and J Strauss, 3607-3709. Amsterdam: Elsevier.

Emerson, Patrick M, and André Portela Souza. 2011. "Is Child Labor Harmful? The Impact of Working Earlier in Life on Adult Earnings." Economic Development and Cultural Change 59 (2): 345-385.

Estevan, Fernanda, and Jean-Marie Baland. 2007. "Mortality Risks, Education and Child Labor." Journal of Development Economics 84 (1): 118-137.

Giné, Xavier, and Dean Yang. 2009. "Insurance, Credit, and Technology Adoption: Field Experimental Evidence from Malawi.” Journal of Development Economics 89 (1): 1-11. 
Gunnarsson, Victoria, Peter F. Orazem, and Mario A. Sánchez. 2006. "Child Labor and School Achievement in Latin America." World Bank Economic Review 20 (1): 31-54.

Heady, Christopher. 2003. "The Effect of Child Labor on Learning Achievement." Word Development 31 (2): 385-398.

Jütting, Johannes P. 2004. "Do Community-based Health Insurance Schemes Improve Poor People's Access to Health Care? Evidence From Rural Senegal." World Development 32 (2): 273-288.

Kassouf, Ana Lúcia, Martin McKee, and Elias Mossialos. 2001. "Early Entrance to the Job Market and Its Effect on Adult Health: Evidence from Brazil." Health Policy and Planning 16 (1): 21-28.

Landmann, Andreas, Björn Vollan, and Markus Frölich. 2012. "Insurance Versus Savings for the Poor: Why One Should Offer Either Both or None." IZA Discussion Paper 6298.

Pakistan Ministry of Health. 2009. National Health Policy 2009: Stepping Towards Better Health (draft 19 Feb 2009). www.pc.gov.pk/Policies/Health.doc.

Pouliot, William. 2006. "Introducing Uncertainty into Baland and Robinson's Model of Child Labour." Journal of Development Economics 79 (1): 264-272.

Qamar, Karim Khan, Peter Knoll, James Roth, and Ayesha Tayyab. 2007. The Beginning of Health Microinsurance in Pakistan. A Review of RSPN-Adamjee Insurance Scheme.

Ranjan, Priya. 2001. "Credit Constraints and the Phenomenon of Child Labor." Journal of Development Economics 64 (1): 81-102.

Rosati, Furio Camillo, and Mariacristina Rossi. 2003. "Children's Working Hours and School Enrollment: Evidence from Pakistan and Nicaragua." The World Bank Economic Review 17 (2): 283-295.

Rosenzweig, Mark R., and Hans P. Binswanger. 1993. "Wealth, Weather Risk and the Composition and Profitability of Agricultural Investments." The Economic Journal 103 (416): 56-78.

Rural Support Programmes Network. 2012. "Outreach.” The Rural Support Programmes Social Mobilisation Newsletter 15. http://www.rspn.org/Outreach/PDFs/outreach_issue_15.pdf.

Wagstaff, Adam. 2010. "Estimating Health Insurance Impacts Under Unobserved Heterogeneity: The Case of Vietnam's Health Care Fund for the Poor." Health Economics 19 (2): 189-208.

Wagstaff, Adam, Magnus Lindelow, Gao Jun, Xu Ling, and Qian Juncheng. 2009. "Extending Health Insurance to the Rural Population: An Impact Evaluation of China's New Cooperative Medical Scheme.” Journal of Health Economics 28 (1): 1-19.

World Bank. 2012. Micro Insurance in Pakistan: A Diagnostic Study. http://www.secp.gov.pk/corporatelaws/pdf/MI_Report_16102012.pdf. 


\section{Appendix}

Figure A1 shows time trends in treatment versus control branches for all outcome variables. These trends reflect the results of specification (1) of Table 6 and provide a visual impression of the sizes of the estimated treatment effects.

Figure A1: Plots of time trends for children's outcomes, by control vs. treatment branches

(a) Child labor incidence

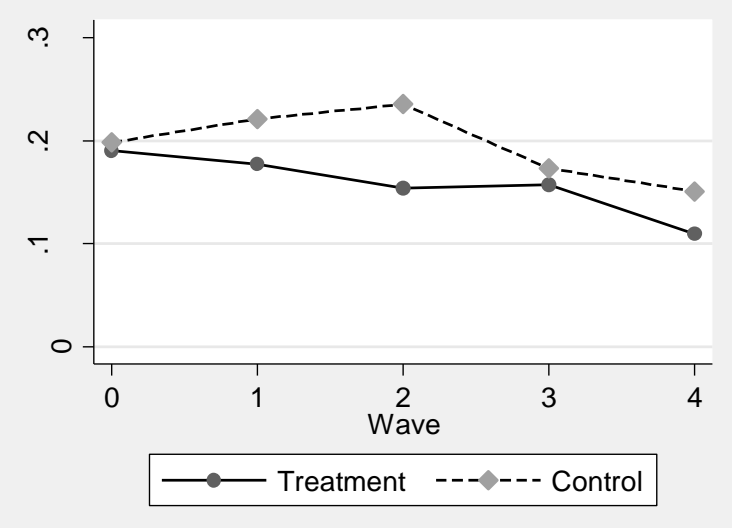

(c) Hazardous occupation

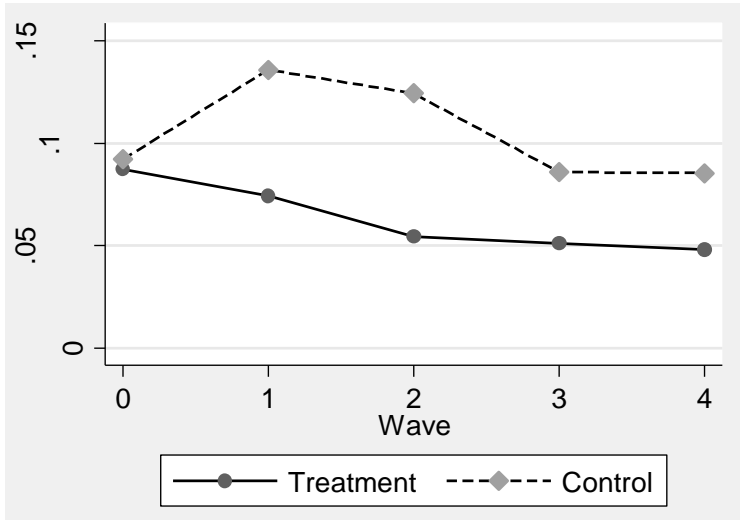

(e) School attendance

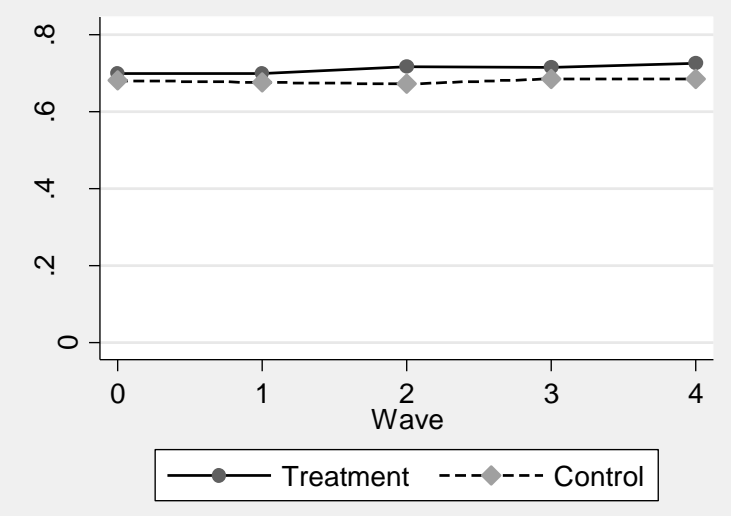

(b) Hours worked

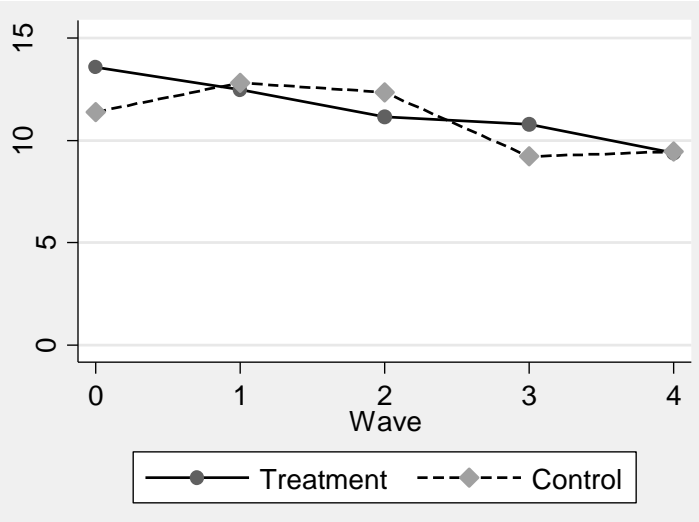

(d) Earnings through child labor

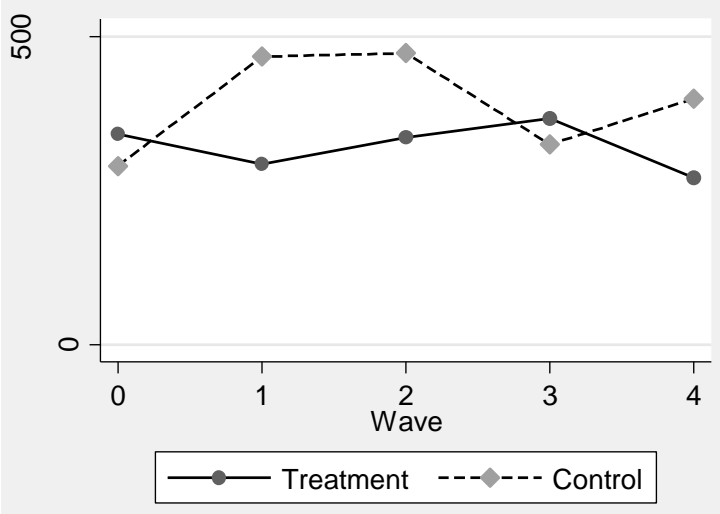

(e) Monthly school days missed

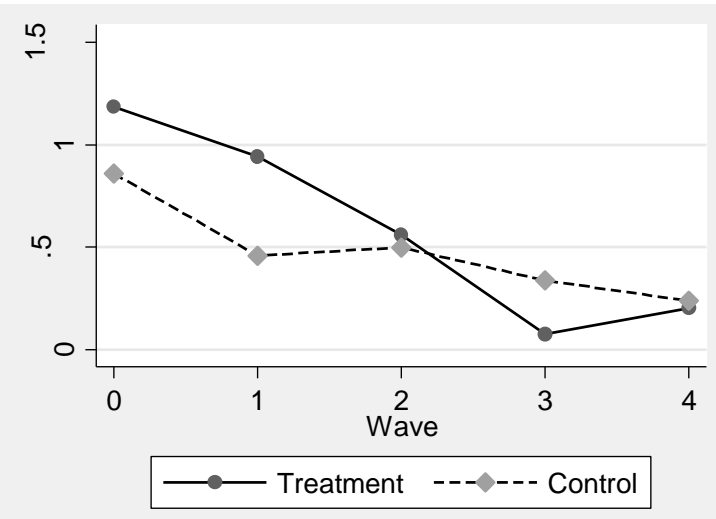


Table A1 complements Tables 6 and 7. Here we show all regression coefficients of specification (2) of Tables 6 and 7, whereas Tables 6 and 7 only reported the coefficient on the treatment indicator. (I.e. the first four rows in Table A1 are identical to the results in Tables 6 and 7.) Most effects of the covariates are plausible: Poorer, older and less educated parents more intensively use child labor. Also economic shocks increase child labor incidence. Girls are significantly less exposed to child labor.

Table A1: Effect of other covariates in regressions on child outcomes -specification (2) from Tables 6+7

\begin{tabular}{|c|c|c|c|c|c|c|}
\hline & $\begin{array}{l}\text { Child } \\
\text { labor }\end{array}$ & $\begin{array}{l}\text { Hours } \\
\text { worked }\end{array}$ & $\begin{array}{c}\text { Child } \\
\text { labor } \\
\text { earnings } \\
\end{array}$ & $\begin{array}{l}\text { Hazardous } \\
\text { occupation }\end{array}$ & $\begin{array}{c}\text { School } \\
\text { attendance }\end{array}$ & $\begin{array}{l}\text { School days } \\
\text { missed }\end{array}$ \\
\hline Treatment Effect 6 months & -0.023 & -1.28 & $-162^{*}$ & $-0.053^{* *}$ & 0.014 & -0.044 \\
\hline Treatment Effect 12 months & $-0.067^{*}$ & -2.78 & $-190 * *$ & $-0.061^{* * *}$ & 0.023 & -0.14 \\
\hline Treatment Effect 18 months & 0.015 & 0.67 & 44.9 & -0.024 & 0.0068 & -0.27 \\
\hline Treatment Effect 24 months & -0.029 & -1.53 & $-191^{* *}$ & -0.033 & 0.026 & -0.18 \\
\hline Poverty Score at baseline (PPI) & $-0.0017^{* * *}$ & $-0.11^{* \star *}$ & $-2.90^{* * *}$ & $-0.0010^{* * *}$ & $0.010^{* * *}$ & $-0.0096^{* \star \star}$ \\
\hline Spouse in household? & $-0.021^{* * *}$ & $-0.88^{* * *}$ & $-107^{\star * *}$ & -0.0034 & 0.0043 & $0.23^{* * *}$ \\
\hline No. of Children age 0-4 & $-0.0055^{*}$ & 0.023 & 0.30 & -0.0037 & -0.0016 & $0.053^{* *}$ \\
\hline No. of Children age 5-13 & -0.0025 & -0.14 & $-16.1^{* \star *}$ & 0.0013 & $0.0063^{* *}$ & $-0.038^{* *}$ \\
\hline No. of Children age 14-17 & $-0.012^{* * *}$ & $-0.57^{\star * *}$ & $-54.2^{\star * *}$ & $-0.0088^{* * *}$ & $0.023^{* * *}$ & 0.025 \\
\hline No. of Adults & $-0.020 * * *$ & $-0.87^{\star * *}$ & $-67.2^{\star \star *}$ & $-0.0083^{* * *}$ & -0.0012 & -0.021 \\
\hline Mean parental age (years) & $0.0014^{* * *}$ & $0.074^{* * *}$ & $4.63^{* * *}$ & $0.00084^{* * *}$ & $-0.0027^{* * *}$ & -0.0026 \\
\hline Mean parental schooling (yrs) & $-0.0054^{\star * *}$ & $-0.31^{* * *}$ & $-9.34^{\star * *}$ & $-0.0016^{* * *}$ & $0.020^{\star * *}$ & 0.00024 \\
\hline Monthly income per capita (a) & $-0.000041^{* * *}$ & $-0.0016^{* * *}$ & $-0.15^{\star * *}$ & $-0.000013^{* * *}$ & $0.000018^{* * *}$ & $-0.000058^{* * *}$ \\
\hline Health shock in family? & $0.046^{* * *}$ & $2.34^{* *}$ & $88.6^{*}$ & -0.0085 & $-0.066^{* * *}$ & 0.23 \\
\hline Non-health shock in family? & $0.066^{* *}$ & 0.66 & -32.3 & -0.0066 & $0.088^{* *}$ & $0.41^{*}$ \\
\hline Death of family member? & 0.0037 & 0.57 & $74.7^{*}$ & $0.022^{* *}$ & $-0.10^{* * *}$ & 0.076 \\
\hline Gender $(0=$ male, $1=$ female $)$ & $-0.085^{* * *}$ & $-3.76^{* \star *}$ & $-526^{* \star \star}$ & $-0.0081^{* *}$ & $0.040^{* * *}$ & -0.040 \\
\hline Age (in years) & $0.034^{* * *}$ & $1.76^{* * *}$ & $74.1^{* * *}$ & $0.011^{* * *}$ & $0.036^{* * *}$ & 0.015 \\
\hline Age 5 - 11 (dummy) & -0.011 & $-11.5^{\star * *}$ & $-294^{* * *}$ & $-0.093^{* * *}$ & $0.35^{* * *}$ & 0.025 \\
\hline Age $12-13$ (dummy) & -0.0070 & $-11.3^{* * *}$ & $-351^{* * *}$ & $-0.083^{* * *}$ & $0.17^{\star * *}$ & -0.021 \\
\hline $\mathrm{N}$ & 20491 & 20487 & 20491 & 20491 & 14930 & 10457 \\
\hline
\end{tabular}

$* * * \mathrm{p}<0.01, * * \mathrm{p}<0.05, * \mathrm{p}<0.1$, standard errors including random effects at the branch-wave level,

${ }^{a}$ adjusted for minor household members (factor 0.6) and excluding income from child labor,

income in Pakistani rupees (1000 Rs = approx. 11\$ US), treatment and wave effects omitted. 
In Table A2 we examine the robustness of the results of Tables 6 and 7 when dropping income as a regressor. In Tables 6 and 7 income was included as a regressor, but its potential endogeneity was noted. The results of Table A2 are similar to those of Tables 6 and 7.

Table A2: Treatment effects on child labor - specification (2) of Tables 6 and 7 without regressor 'income'

\begin{tabular}{l|cccccc}
\hline \hline & $\begin{array}{c}\text { Child } \\
\text { labor }\end{array}$ & $\begin{array}{c}\text { Hours } \\
\text { worked }\end{array}$ & $\begin{array}{c}\text { Child } \\
\text { labor } \\
\text { earnings }\end{array}$ & $\begin{array}{c}\text { Hazardous } \\
\text { occupation }\end{array}$ & $\begin{array}{c}\text { School } \\
\text { attendance }\end{array}$ & $\begin{array}{c}\text { Days } \\
\text { missed }\end{array}$ \\
\hline \hline Treatment Effect 6 months & -0.030 & -1.55 & $\mathbf{- 1 8 5 *}$ & $\mathbf{- 0 . 0 5 3 * * *}$ & 0.0018 & 0.20 \\
& $(0.040)$ & $(1.74)$ & $(95.6)$ & $(0.020)$ & $(0.029)$ & $(0.46)$ \\
Treatment Effect 12 months & -0.063 & -2.60 & $\mathbf{- 1 7 2 *}$ & $\mathbf{- 0 . 0 5 9 * * *}$ & 0.020 & -0.12 \\
& $(0.039)$ & $(1.70)$ & $(93.4)$ & $(0.020)$ & $(0.029)$ & $(0.46)$ \\
Treatment Effect 18 months & 0.0082 & 0.40 & 21.2 & -0.026 & 0.0086 & -0.26 \\
& $(0.039)$ & $(1.70)$ & $(93.5)$ & $(0.020)$ & $(0.029)$ & $(0.46)$ \\
Treatment Effect 24 months & -0.020 & -1.19 & $\mathbf{- 1 5 8 *}$ & -0.031 & 0.021 & -0.15 \\
& $(0.039)$ & $(1.70)$ & $(93.7)$ & $(0.021)$ & $(0.029)$ & $(0.46)$ \\
\hline Controls (without income) ${ }^{\text {a }}$ & YES & YES & YES & YES & YES & YES \\
N & 20,491 & 20,487 & 20,491 & 21,176 & 15,415 & 10,526 \\
\hline \hline
\end{tabular}

Similarly, Table A3 complements Table 8 when dropping income as regressor in specification (3). Again, results remain similar.

Table A3: Disentangling treatment effects on children's outcomes - specification as in Table 8 without the regressor 'income'

\begin{tabular}{|c|c|c|c|c|c|c|}
\hline & $\begin{array}{l}\text { Child } \\
\text { labor }\end{array}$ & $\begin{array}{c}\text { Hours } \\
\text { worked }\end{array}$ & $\begin{array}{c}\text { Child } \\
\text { labor } \\
\text { earnings }\end{array}$ & $\begin{array}{l}\text { Hazardous } \\
\text { occupation }\end{array}$ & $\begin{array}{c}\text { School } \\
\text { attendance }\end{array}$ & $\begin{array}{l}\text { Days } \\
\text { missed }\end{array}$ \\
\hline TE 6 months - mandatory & 0.040 & 1.49 & -74.2 & -0.022 & -0.027 & $0.83 *$ \\
\hline TE 12 months - mandatory & 0.024 & 1.23 & -47.8 & -0.027 & 0.011 & 0.49 \\
\hline TE 18 months - mandatory & $0.096 *$ & 2.82 & 107 & -0.0095 & -0.013 & 0.62 \\
\hline TE 24 months - mandatory & 0.075 & 1.95 & -40.2 & 0.0090 & 0.024 & 0.65 \\
\hline$\Delta \mathrm{TE} 6$ months - voluntary & $-0.090 * *$ & $-3.91 * *$ & -149 & -0.040 & 0.042 & $-0.92 * * *$ \\
\hline$\Delta \mathrm{TE} 12$ months - voluntary & $-0.11 * * *$ & $-5.08 * * *$ & -164 & $-0.044 *$ & 0.018 & $-0.90 * * *$ \\
\hline$\Delta \mathrm{TE} 18$ months - voluntary & $-0.12 * * *$ & $-3.07 *$ & -109 & -0.023 & 0.030 & $-1.32 * * *$ \\
\hline$\Delta$ TE 24 months - voluntary & $-0.13 * * *$ & $-4.14 * * *$ & -162 & $-0.056 * *$ & -0.00052 & $-1.20 * * *$ \\
\hline Controls (without income) $^{\mathrm{a}}$ & YES & YES & YES & YES & YES & YES \\
\hline $\mathrm{N}$ & 20,491 & 20,487 & 20,491 & 21,176 & 15,415 & 10,526 \\
\hline
\end{tabular}


Table A4 complements Table 8 and shows estimates for various alternative definitions of child labor, where we vary the amount of hours required before being considered a child laborer. These alternative classifications differ from the ILO definition and are based only on hours worked, not on type of activity. (This explains the slight variation between the sample sizes.) In the second column a child is only defined as a child laborer if working at least 5 hours (if 11 years old or younger), at least 20 hours (if 14 years old or younger) or at least 43 hours (if older than 14 years) per week. In the last column, only children working very many hours are coded as child laborers, i.e. if working at least 10 hours (if 11 years old or younger), at least 30 hours (if 14 years old or younger) or at least 50 hours (if older than 14 years). The estimation results for the coverage effect are robust to these alternative definitions.

Table A4: Disentangling treatment effects on children's outcomes - alternative child labor definitions

\begin{tabular}{|c|c|c|c|}
\hline & $\begin{array}{c}\text { Child labor } \\
\text { (ILO definition) }\end{array}$ & $\begin{array}{c}\text { Child laborer if } \\
\text { working many } \\
\text { hours }^{\text {a }}\end{array}$ & $\begin{array}{l}\text { Child laborer if } \\
\text { working very } \\
\text { many hours }\end{array}$ \\
\hline Treatment effect 6 months - mandatory & 0.046 & 0.051 & $0.063 *$ \\
\hline Treatment effect 12 months - mandatory & 0.019 & 0.020 & 0.024 \\
\hline Treatment effect 18 months - mandatory & $0.10 * *$ & $0.12 * * *$ & $0.092 * * *$ \\
\hline Treatment effect 24 months - mandatory & 0.069 & $0.068 *$ & $0.073 * *$ \\
\hline$\Delta$ Treatment effect 6 months - voluntary & $-0.088 * *$ & -0.058 & $-0.063 * *$ \\
\hline$\Delta$ Treatment effect 12 months - voluntary & $-0.12 * * *$ & $-0.090 * * *$ & $-0.11 * * *$ \\
\hline$\Delta$ Treatment effect 18 months - voluntary & $-0.12 * * *$ & $-0.095 * * *$ & $-0.082 * * *$ \\
\hline$\Delta$ Treatment effect 24 months - voluntary & $-0.13 * * *$ & $-0.11 * * *$ & $-0.11 * * *$ \\
\hline $\begin{array}{l}\text { Controls } \\
\mathrm{N}\end{array}$ & $\begin{array}{c}\text { YES } \\
20,491\end{array}$ & $\begin{array}{c}\text { YES } \\
20,487\end{array}$ & $\begin{array}{c}\text { YES } \\
20,487\end{array}$ \\
\hline
\end{tabular}


Table A5 complements Table 9 and examines the sensitivity to the definition of a health shock. Instead of excluding households that received a claim payment at some point in time (as we do in Table 9), we exclude in Table A5 all households that at any time reported a death or a health case. The estimates for the coverage effect remain stable.

Table A5: Disentangling treatment effects on children's outcomes - ruling out insurance payment effects (without households with injuries/deaths at any time)

\begin{tabular}{|c|c|c|c|c|c|c|}
\hline & $\begin{array}{l}\text { Child } \\
\text { labor }\end{array}$ & $\begin{array}{c}\text { Hours } \\
\text { worked }\end{array}$ & $\begin{array}{c}\text { Child } \\
\text { labor } \\
\text { earnings }\end{array}$ & $\begin{array}{l}\text { Hazardous } \\
\text { occupation }\end{array}$ & $\begin{array}{c}\text { School } \\
\text { attendance }\end{array}$ & $\begin{array}{l}\text { Days } \\
\text { missed }\end{array}$ \\
\hline TE 6 months - mandatory & 0.063 & 2.08 & -63.6 & -0.026 & -0.033 & $0.77 * *$ \\
\hline TE 12 months - mandatory & 0.018 & 0.65 & -48.4 & -0.039 & 0.00041 & $1.31 * * *$ \\
\hline TE 18 months - mandatory & $0.10 * *$ & 2.74 & 117 & -0.014 & -0.033 & $\mathbf{0 . 8 8} * *$ \\
\hline TE 24 months - mandatory & 0.067 & 1.38 & -45.9 & 0.0025 & 0.0028 & $0.97 * * *$ \\
\hline$\Delta \mathrm{TE} 6$ months - voluntary & $-0.097 * *$ & $-3.97 * *$ & -122 & -0.030 & 0.072 & $-0.97 * * *$ \\
\hline$\Delta \mathrm{TE} 12$ months - voluntary & $-0.11 * * *$ & $-4.14 * *$ & -169 & -0.030 & 0.032 & $-1.52 * * *$ \\
\hline$\Delta \mathrm{TE} 18$ months - voluntary & $-0.12 * * *$ & $-3.20 *$ & -145 & -0.0074 & 0.048 & $-1.44 * * *$ \\
\hline$\Delta \mathrm{TE} 24$ months - voluntary & $-0.14 * * *$ & $-4.43 * *$ & $-211 *$ & $-0.054 *$ & 0.0057 & $-1.42 * * *$ \\
\hline Controls & YES & YES & YES & YES & YES & YES \\
\hline $\mathrm{N}$ & 14,321 & 14,317 & 14,321 & 14,321 & 10,415 & 7,106 \\
\hline
\end{tabular}

\section{Appendix B - Supplementary background statistics}

The following supplementary tables are meant to provide some further background information about the situation in Pakistan, e.g. about the serial correlation of child labor and about the importance of insurance payouts for health expenditures. All statistics and regressions are rather descriptive and are therefore not included in the main text. They shall provide an impression of how important certain correlations are in our data set.

In Table B1 we examine child labor and how it is correlated over time. We find that child labor status is rather persistent across waves. Even though changes occur, more than half of the child laborers in one period $\left(\mathrm{CL}_{\mathrm{t}-1}=1\right)$ remain child laborers in the follow-up period $\left(\mathrm{CL}_{t}=1\right)$. This is true for treatment and control branches. On the other hand, only about $10 \%$ of the non-child laborers from the previous period $\left(\mathrm{CL}_{\mathrm{t}-1}=0\right)$ become child laborers in the next period $\left(\mathrm{CL}_{\mathrm{t}}=1\right)$. Especially compared with child laborers from the pre-period, their risk is 
substantially lower. This strong serial correlation indicates that the decision about sending children to work is not taken independently in each period.

Table B1: Persistence of Child labor prevalence over time, control vs. treatment branches

\begin{tabular}{l|ccc|ccc}
\hline \hline & \multicolumn{3}{|c|}{ Fraction of children providing child labor in period t, by child labor status in t-1 } \\
\hline & \multicolumn{3}{|c|}{ Control branches } & \multicolumn{3}{c}{ Treatment branches } \\
\hline & ALL & $\begin{array}{c}\text { No child } \\
\text { labor in } \\
\text { time t-1 }\end{array}$ & $\begin{array}{c}\text { Child } \\
\text { laborer in } \\
\text { time t-1 }\end{array}$ & ALL & $\begin{array}{c}\text { No child } \\
\text { labor in } \\
\text { time t-1 }\end{array}$ & $\begin{array}{c}\text { Child } \\
\text { laborer in } \\
\text { time t-1 }\end{array}$ \\
\hline Baseline & 0.20 & & & 0.19 & 0.10 & 0.65 \\
6 months & 0.22 & 0.14 & 0.56 & 0.18 & 0.07 & 0.53 \\
12 months & 0.24 & 0.12 & 0.69 & 0.15 & 0.09 & 0.58 \\
18 months & 0.17 & 0.09 & 0.51 & 0.16 & 0.05 & 0.40 \\
24 months & 0.15 & 0.08 & 0.55 & 0.11 & \\
\hline \hline
\end{tabular}

In Table B2 we examine health expenditures of households. The first panel of Table B2 shows how monthly health expenditures vary with reported injuries and illnesses. (The panels (b) and (c) examine treatment and control branches separately.) We control for wave and household fixed effects. We see that overall health expenditures increase over time, starting at about 500 rupees per month at baseline. A reported injury or illness almost doubles health expenditures, while a paid claim reduces a substantial part of those extra expenditures. Effects are generally stronger for hospitalization expenditures: At baseline the average cost is less than 80 rupees and a reported injury or illness is associated with an increase of more than 400 rupees. For cases with reimbursement the health expenses increase substantially less. This is consistent with the insurance scheme that helps to cover expenditures of hospitalization.

Panels (b) and (c) of Table B2 show the same analysis for treatment and control branches separately. The effects are estimated with less precision, especially for control branches, but qualitatively the results remain the same, particularly for hospitalization expenditures. A reported injury or illness increases expenditures for hospitalization in particular, while a paid claim substantially reduces extra expenditures. 
Table B2: Fixed effects regression of monthly household health expenditures on health shocks

a) All branches

\begin{tabular}{l|ccc}
\hline \hline & All & Outpatient & Hospitalization \\
\hline \hline Injury/illness case happened & $\mathbf{4 6 5 * * *}$ & $\mathbf{5 0 . 7} * *$ & $\mathbf{4 1 4 * * *}$ \\
Injury/illness paid by insurance & $\mathbf{- 2 1 2} * * *$ & -58.0 & $\mathbf{- 1 5 5 * *}$ \\
\hline Time dummy: 6 months & $41.3 * *$ & $27.4 * *$ & 13.5 \\
Time dummy: 12 months & $81.8 * * *$ & $49.9 * * *$ & $33.0 * *$ \\
Time dummy: 18 months & $241 * * *$ & $130 * * *$ & $111^{* * *}$ \\
Time dummy: 24 months & $253^{* * *}$ & $244 * * *$ & 8.82 \\
\hline Constant & $503 * * *$ & $424 * * *$ & $78.7 * * *$ \\
\hline Household fixed effects? & YES & YES & YES \\
$\quad \mathrm{N}$ & 10,102 & 10,103 & 10,091 \\
\hline \hline
\end{tabular}

b) Treatment branches only

\begin{tabular}{l|ccc}
\hline \hline & All & Outpatient & Hospitalization \\
\hline \hline Injury/illness case happened & $\mathbf{5 1 1} * * *$ & 28.5 & $\mathbf{4 8 3} * * *$ \\
Injury/illness paid by insurance & $\mathbf{- 1 8 0 *}$ & -39.2 & $\mathbf{- 1 4 1 * *}$ \\
- \hdashline Time dummy: 6 months & $102 * * *$ & $90.2 * * *$ & 11.6 \\
Time dummy: 12 months & $52.0 * *$ & $73.8 * * *$ & -21.8 \\
Time dummy: 18 months & $252 * * *$ & $156^{* * *}$ & $96.3 * * *$ \\
Time dummy: 24 months & $166^{* * *}$ & $175^{* * *}$ & -8.95 \\
Constant & $440 * * *$ & $380 * * *$ & $60.7 * * *$ \\
\hline Household fixed effects? & YES & YES & YES \\
$\quad \mathrm{N}$ & 6,352 & 6,352 & 6,350 \\
\hline \hline
\end{tabular}

c) Control branches only

\begin{tabular}{l|ccc}
\hline \hline & All & Outpatient & Hospitalization \\
\hline \hline Injury/illness case happened & $\mathbf{1 4 1} *$ & -8.79 & $\mathbf{1 4 7 * * *}$ \\
Injury/illness paid by insurance & -168 & -28.1 & -140 \\
\hline Time dummy: 6 months & -52.7 & $-69.3 * * *$ & 15.8 \\
Time dummy: 12 months & $142 * * *$ & 16.2 & $129 * * *$ \\
Time dummy: 18 months & $231 * * *$ & $94.7 * * *$ & $136 * * *$ \\
Time dummy: 24 months & $411 * * *$ & $362 * * *$ & $50.1 *$ \\
\hline Constant & $610 * * *$ & $501 * * *$ & $109 * * *$ \\
\hline Household fixed effects? & YES & YES & YES \\
$\mathrm{N}$ & 3,750 & 3,751 & 3,741 \\
\hline \hline
\end{tabular}

'Injury/illness case' indicates that someone in the household reported an injury or hospitalization, 'Injury/illness paid' indicates whether a reimbursement of expenditures by the insurance took place.

Table B3 examines how households in treatment branches make use of the option to voluntarily insure additional household members. We examine whether households in treatment branches use the option of coverage extension to insure the entire household or whether they pick only selected members to be insured. Table B3 shows which fraction of the eligible household members is voluntarily insured. For a meaningful analysis we examine only those households with at least two eligible members, living in treatment areas. The table thus shows whether households insure individual members selectively (maybe based on risk characteristics), or whether households rather opt for complete coverage. At baseline, none of the additional household members is insured (since insurance was not yet available then). 
After 6 months there is a mixed picture. More than half of the households opt for complete (i.e. share equals 1 ) or zero coverage (i.e. share equals 0 ), but the other half only covered a part of the household. However, after 12 and 18 months there is a clear tendency to cover either all or none of the potentially insured: about $80 \%$ of the households have either complete or zero insurance coverage. This tendency remains stable when only considering those households that currently have a loan with NRSP. Hence, although some households remain that deliberately choose whom to insure, most households insure everyone or none at all.

Table B3: Distribution [\%] of shares of voluntarily insured per household, per wave

\begin{tabular}{c|cccc}
\hline $\begin{array}{c}\text { Share of additional } \\
\text { Household members } \\
\text { insured }\end{array}$ & baseline & 6 months & 12 months & 18 months \\
\hline 0 & 100.00 & 7.66 & 36.12 & 38.13 \\
$0.01-0.10$ & 0.00 & 0.00 & 0.00 & 0.00 \\
$0.11-0.20$ & 0.00 & 1.72 & 0.00 & 1.07 \\
$0.21-0.30$ & 0.00 & 3.75 & 0.79 & 2.30 \\
$0.31-0.40$ & 0.00 & 5.94 & 2.21 & 1.53 \\
$0.41-0.50$ & 0.00 & 15.16 & 6.62 & 7.81 \\
$0.51-0.60$ & 0.00 & 1.41 & 0.00 & 0.46 \\
$0.61-0.70$ & 0.00 & 8.59 & 5.05 & 6.43 \\
$0.71-0.80$ & 0.00 & 5.78 & 3.63 & 3.22 \\
$0.81-0.90$ & 0.00 & 5.94 & 3.15 & 2.30 \\
$0.91-0.99$ & 0.00 & 0.16 & 0.00 & 0.00 \\
1 & 0.00 & 43.91 & 42.43 & 36.75 \\
\hline $\mathrm{N}$ & 602 & 640 & 634 & 653 \\
\hline \hline
\end{tabular}

Note: Only households in treatment branches and with at least two potential voluntary members are considered. Example: Consider a household with 3 additional adult members, of whom 1 is voluntarily insured, i.e. $33 \%$.

In Table B4 we examine who becomes voluntarily insured. We regress the insurance status on individual and household characteristics, using logit regression. The table shows marginal effects. We cluster standard errors at the household level and capture the decreasing time trend in voluntary coverage (apparent also in Figure 3(c)) by controlling for wave dummies. On the individual level, gender and age are significantly related to coverage. While males are covered with higher probability, household members who are between 25 and 35 years old have the highest coverage rate. Older individuals have a lower probability of receiving additional coverage. A nonparametric plot of the insurance probability as a function of age and gender is shown in Figure B1.

Table B4 also shows the effects of household characteristics. We find that voluntary insurance is more likely to be purchased by less educated, older and wealthier clients. Also the number 
of children in the household is positively related to additional coverage, in contrast to the number of adults which is negatively related to uptake.

Table B4: Logit regression of additional insurance uptake on individual and household characteristics

\begin{tabular}{l|c}
\hline & All \\
\hline \hline Time dummy: 12 months & $\mathbf{- 0 . 1 5} * * *$ \\
Time dummy: 18 months & $\mathbf{- 0 . 2 3} * * *$ \\
\hline Gender $(0=$ male, $1=$ female) & $\mathbf{- 0 . 0 3 0} * *$ \\
Age & $\mathbf{0 . 0 1 9} * * *$ \\
Age squared & $\mathbf{- 0 . 0 0 0 2 9} * * *$ \\
Age $0-4$ & $\mathbf{0 . 2 0} * * *$ \\
Age $5-11$ & $\mathbf{0 . 1 1} *$ \\
Age $12-13$ & -0.019 \\
Age $14-17$ & $\mathbf{- 0 . 0 9 4}$ \\
Education & 0.0021 \\
\hline Mean parental education (years) & $\mathbf{- 0 . 0 0 6 3 *}$ \\
Mean parental age & $\mathbf{0 . 0 0 2 5} *$ \\
Monthly income per capita (in 1000 Rs.) & $\mathbf{0 . 1 7} * * *$ \\
Monthly income per capita (in 1000 Rs.) squared & $\mathbf{- 0 . 0 1 2} * * *$ \\
Spouse in household? & -0.032 \\
No. of Children age $0-4$ & $\mathbf{0 . 0 3 8} * *$ \\
No. of Children age $5-13$ & $\mathbf{0 . 0 1 9}$ \\
No. of Children age $14-17$ & $\mathbf{0 . 0 3 9} * * *$ \\
No. of Adults & $\mathbf{- 0 . 0 1 6} * *$ \\
\hline N & 7,819 \\
\hline
\end{tabular}

Marginal effects shown, $* * * \mathrm{p}<0.01, * * \mathrm{p}<0.05, * \mathrm{p}<0.1$, standard errors clustered on household level, "parental" indicates characteristics of the client and spouse.

Figure B1: Plots of additional insurance uptake, by age and gender

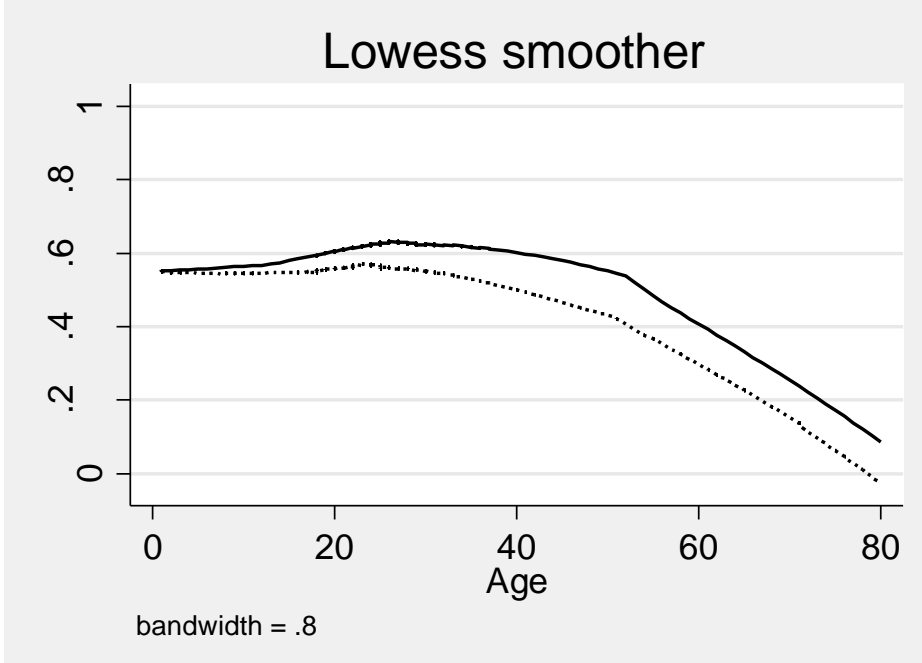

Note: Male (solid line) and female (dotted line) 


\section{Appendix C - Modeling child labor decisions by households}

In the absence of an adequate benchmark model from the theoretical child labor literature (as discussed in the main text), we develop a simple model of the role of risk for child labor input. We consider two periods within childhood. In both periods, parents take a decision about the amount of child labor $l_{t}^{c}$. They take negative consequences of child labor into account (such as the trade-off with school attendance and learning) by attaching a positive utility (with weight $\gamma>0$ ) to child leisure $1-l_{t}^{c}$. (Note that we define the time where the child does not work as "child leisure". Leisure time thus also includes the time in school and time for school homework. This definition might deviate from what the child itself considers as leisure time.)

On the other hand, they benefit from the income generated by child labor through consumption $c_{t}$ in each period:

$$
U_{t}=\log c_{t}+\gamma \log \left(1-l_{t}^{c}\right)
$$

Child labor is restricted to the interval $l_{t}^{c} \in[0,1]$. The log-shape of the utility function implies that the household is risk-averse. Households maximize expected total utility as defined by:

$$
\tilde{E}\left[\sum_{t=1}^{2} \sigma^{t-1} U_{t}\right]
$$

where $\sigma \leq 1$ is a discount factor and the expected value $\tilde{E}$ depends on the subjective expectation of a health shock defined below. We thus permit that the subjective probability of shocks may deviate from the true probability, i.e. households may overestimate the risk of rare events such as catastrophic health shocks.

Household income is generated by adults who supply labor inelastically, generating wage income $w_{A}$, and children supplying labor at wage rate $w_{C}$, generating income $w_{C} l_{t}^{c}$. In each period there is the risk of a (health) shock $\left(\theta_{t}=1\right)$, which generates additional (health) expenditures $S$ to be paid. (We indicate the absence of a shock by $\theta_{t}=0$.) A shock occurs with probability $p$, this is the true or objective shock probability. The household, on the other hand, expects the shock to happen with probability $p_{\theta}$ (subjective probability). This subjective probability is relevant for the decision making of the household, whereas the objective probability will be relevant later when a fair insurance is introduced. In each period t, shocks are observed prior to child labor and consumption choices. We allow for an initial 
endowment $e_{1}$. The budget constraint imposes that over the two periods total spending equals the budget:

$$
\begin{array}{ll}
\sum_{t=1}^{2} c_{t} \leq \sum_{t=1}^{2}\left(w_{A}+l_{t}^{c} w_{C}-\theta_{t} S\right)+e_{1} & \text { or equivalently } \\
\sum_{t=1}^{2}\left(c_{t}+\left(1-l_{t}^{c}\right) w_{C}\right) \leq \sum_{t=1}^{2}\left(w_{A}+w_{C}-\theta_{t} S\right)+e_{1} &
\end{array}
$$

To simplify the notation we define the total potential budget as

$$
Y\left(\theta_{1}, \theta_{2}\right):=\sum_{t=1}^{2}\left(w_{A}+w_{C}-\theta_{t} S\right)+e_{1}=2 w_{A}+2 w_{C}-\left(\theta_{1}+\theta_{2}\right) S+e_{1}
$$

which is the hypothetical budget if the child worked full-time, i.e zero leisure. Define also

$$
Y_{t}=c_{t}+\left(1-l_{t}^{c}\right) w_{C}
$$

which can be interpreted as the budget in period $t$ which is spent on buying consumption goods and consuming child leisure $\left(1-l_{t}^{c}\right)$ at price $w_{C}$. (Hence, child leisure can be considered as a type of consumption, and $Y_{t}$ is therefore not the real budget used, but total consumption consisting of consuming goods plus opportunity costs of foregone child labor earnings.) With this notation we can write the budget constraint equation (4) as

$$
Y_{1}+Y_{2} \leq Y\left(\theta_{1}, \theta_{2}\right)
$$

with strict equality for optimal household decisions.

Note that while we have no limit on borrowing or saving between the two periods, there is a limited time horizon ending after two periods. ${ }^{16}$ This simplifying assumption is imposed to ease the tractability of the model. Solving the model requires specifying how to split money between periods (intertemporal decision) and how to allocate the period specific budget between consumption of goods and child leisure (intratemporal decision). We present first the intratemporal decision on allocation of a given period-specific budget between consumption and child leisure. Next, we show a solution for the intertemporal decision on how much budget to allocate to each period. Lastly, we use the results from the model to address the implications of an insurance policy.

\footnotetext{
${ }^{16}$ It might seem arbitrary that 'smoothing forward' via credits is not possible in the second period. Modeling a more dynamic setting, e.g. via Bellmann equations, is probably more realistic. However, it would make the formal problem much more complicated and our main goal is to show in a simple way that changing risk in the future already creates incentives for child labor today. These incentives will also show up in a more dynamic setting, especially if we introduce borrowing limits or an aversion to indebtedness.
} 


\section{The intratemporal problem}

In each period the utility to be maximized is

$$
\max _{c_{t}, l_{t}^{c}} U_{t}=\max _{c_{t}, l_{t}^{c}} \log \left(c_{t}\right)+\gamma \log \left(1-l_{t}^{c}\right)
$$

or with the budget constraint plugged in for consumption

$$
\max _{l_{t}^{c}} U_{t}=\max _{l_{t}^{c}} \log \left(Y_{t}-\left(1-l_{t}^{c}\right) w_{C}\right)+\gamma \log \left(1-l_{t}^{c}\right)
$$

If the budget available in each period is large relative to the child wage rate $w_{C}$, we might be at a corner solution where the optimal choice of child labor is $l_{t}^{c}=0$. Yet, if we focus on very poor households, they would always supply a bit of child labor such that we would observe interior solutions. Assuming that the household is very poor, we can ignore corner solutions and solve the household decision making via the first order condition:

$$
\begin{aligned}
\frac{\partial U_{t}}{\partial l_{t}^{c}}= & \frac{w_{C}}{Y_{t}-\left(1-l_{t}^{c}\right) w_{C}}-\frac{\gamma}{1-l_{t}^{c}}=0 \\
& \Rightarrow w_{C}\left(1-l_{t}^{c}\right)=\gamma\left(Y_{t}-\left(1-l_{t}^{c}\right) w_{C}\right) \\
& \Leftrightarrow w_{C}\left(1-l_{t}^{c}\right)(1+\gamma)=\gamma Y_{t} \\
& \Leftrightarrow\left(1-l_{t}^{c}\right)=\frac{\gamma}{1+\gamma} \frac{Y_{t}}{w_{C}}
\end{aligned}
$$

Inserting this result in the budget constraint we obtain

$$
c_{t}=Y_{t}-\left(1-l_{t}^{c}\right) w_{c}=\frac{1}{1+\gamma} Y_{t}
$$

Hence, we obtain the usual result that the household likes to spend a fraction $\frac{\gamma}{1+\gamma}$ of the budget on the good 'child leisure' at price $w_{C}$ and a fraction $\frac{1}{1+\gamma}$ on consumption at price 1 . The utility derived from the solution is

$$
U_{t}=\log \left(\frac{1}{1+\gamma} Y_{t}\right)+\gamma \log \left(\frac{\gamma}{1+\gamma} \frac{Y_{t}}{w_{C}}\right)
$$

The marginal utility from having one unit increase in the period-specific budget $Y_{t}$ is then

$$
\frac{\partial U_{t}}{\partial Y_{t}}=\frac{1+\gamma}{Y_{t}}
$$




\section{The intertemporal problem}

Having solved the intratemporal optimization we know the utility that can be derived from a given budget $Y_{t}$ in each period. In particular, equation (6) gives the marginal utility, which should be equalized across periods. The intertemporal decision on how to split the budget between periods will be driven by the overall utility function of the household. It consists of the first period utility and the expected discounted second period utility:

$$
U=U_{1}\left(Y_{1}\right)+\sigma \tilde{E}\left[U_{2}\left(Y_{2}\right)\right]
$$

Note that the household knows the shock realization $\theta_{1}$ in period 1 before taking any decision on consumption and child labor in the first period. Therefore, no expectation is involved in the first period utility part. On the other hand, $\theta_{2}$ is unknown when making consumption and labor supply decisions for the first period. Total utility only depends on the budget available in both periods, which is used for consumption of child leisure and of goods. In equation (6) we have derived the marginal utility of money. For optimality of the budget split between the two periods we will need that the marginal utility of money in the first period equals the expected discounted marginal utility of money in the second period:

$$
\frac{\partial U_{1}\left(Y_{1}\right)}{\partial Y_{1}}=\frac{\partial \sigma \tilde{E}\left[U_{2}\left(Y_{2}\right)\right]}{\partial Y_{2}}
$$

We can derive the expected discounted marginal utility for the second period by making use of (6) and the budget constraint (5) and remembering that a shock is expected with subjective probability $p_{\theta}$ :

$$
\frac{\partial \sigma \tilde{E}\left[U_{2}\left(Y_{2}\right)\right]}{\partial Y_{2}}=\sigma p_{\theta} \frac{1+\gamma}{Y\left(\theta_{1}, 1\right)-Y_{1}}+\sigma\left(1-p_{\theta}\right) \frac{1+\gamma}{Y\left(\theta_{1}, 0\right)-Y_{1}}
$$

It will be helpful to define a function $f$ as the difference between the marginal utility of money in period 1 and period 2:

$$
f\left(Y_{1} ; \theta_{1}\right) \equiv \frac{\partial U_{1}}{\partial Y_{1}}-\frac{\partial \sigma \tilde{E}\left[U_{2}\left(Y_{2}\right)\right]}{\partial Y_{2}}=\frac{1+\gamma}{Y_{1}}-\sigma p_{\theta} \frac{1+\gamma}{Y\left(\theta_{1}, 1\right)-Y_{1}}-\sigma\left(1-p_{\theta}\right) \frac{1+\gamma}{Y\left(\theta_{1}, 0\right)-Y_{1}} .
$$

$f\left(Y_{1} ; \theta_{1}\right)$ depends on the shock status $\theta_{1}$ in period 1 and on the choice variable $Y_{1}$. For a particular choice of $Y_{1}$, the consumption of leisure and goods in time period two, i.e. $Y_{2}$, is fixed via the budget constraint (5). The optimal choice of $Y_{1}$, given $\theta_{1}$, is determined by the equilibrium condition (7), which we can re-write in terms of the function $f$ as: 


$$
f\left(Y_{1}^{\text {optimal }} ; \theta_{1}\right)=0
$$

For a value $Y_{1}$ where $f\left(Y_{1} ; \theta_{1}\right)$ is positive, marginal utility of money is larger in the first period than in the second period, such that there would be an incentive to shift some consumption from period 2 to period 1, i.e. to increase $Y_{1}$. This will be the case for low levels of $Y_{1}$. The reverse is true for large values of $Y_{1}$. Formally, the function $f$ is strictly decreasing in the choice variable $Y_{1}$ in the domain $\left[0, Y\left(\theta_{1}, 1\right)\right]$, starting out from $f(0)=\infty$ and reaching $f\left(Y\left(\theta_{1}, 1\right)\right)=-\infty$. Hence, there must be a unique $Y_{1}$ satisfying the equilibrium condition (7). This unique $Y_{1}$ depends on $\theta_{1}$, and it determines child labor in period 1. Future child labor then only depends on the realization of the shock in period 2 and the resulting budget.

\section{The policy intervention: insurance}

The effect of introducing an actuarially fair insurance can be modeled by reducing the shock cost (i.e. health expenditures) by the indemnity payment $I$ (where $I \leq S$, i.e. the indemnity payment is not larger than the health shock) and at the same time reducing income by the fair premium $I p$, where $p$ is the objective shock probability, i.e. the true probability of a shock. If insurance is bought for both periods, the potential budget will now become

$$
Y\left(\theta_{1}, \theta_{2}\right)=2 w_{A}+2 w_{C}+e_{1}-\left(\theta_{1}+\theta_{2}\right) S+\left(\theta_{1}+\theta_{2}\right) I-2 \cdot I p
$$

where $\left(\theta_{1}+\theta_{2}\right) I$ is the indemnity payment in case of a shock in period 1 and/or period 2 . The premium to be paid for the insurance in both periods together is $2 \cdot I p$.

We also consider the case if insurance is bought only for one period. We consider particularly the case where insurance is only bought for the second period in order to analyze the ex-ante effects in the first period. If only the second period is insured, the potential budget becomes

$$
Y\left(\theta_{1}, \theta_{2}\right)=2 w_{A}+2 w_{C}+e_{1}-\left(\theta_{1}+\theta_{2}\right) S+\theta_{2} I-I p
$$

where only the second period shock is insured and the premium payment is therefore only $I p$. If the indemnity $I$ is zero, i.e. no insurance, the potential budget in (9) and (10) simplifies to the budget of the previous subsection.

From equations (9) and (10) we can calculate the marginal effects of increasing insurance on the potential budget, which will be used to examine the effects of insurance on child labor 
below. The total effect of the insurance on the overall budget depends on the periods covered and on the different shock realizations:

Table C1: Budget effect of insurance in different situations

\begin{tabular}{|c|c|c|}
\hline & $\begin{array}{l}\text { Insurance bought for } \\
\text { period } 2 \text { only }\end{array}$ & $\begin{array}{l}\text { Insurance bought for } \\
\text { both periods }\end{array}$ \\
\hline $\begin{array}{l}\text { No shock in period } 1 \\
\text { i.e. } \theta_{1}=0\end{array}$ & $\begin{array}{l}\text { Case I: } \\
\qquad \begin{aligned} \frac{\partial Y(0,0)}{\partial I} & =-p \\
\frac{\partial Y(0,1)}{\partial I} & =1-p\end{aligned}\end{array}$ & $\begin{array}{l}\text { Case III: } \\
\qquad \begin{aligned} \frac{\partial Y(0,0)}{\partial I} & =-2 p \\
\frac{\partial Y(0,1)}{\partial I} & =1-2 p\end{aligned}\end{array}$ \\
\hline $\begin{array}{l}\text { Shock in period } 1 \\
\text { i.e. } \theta_{1}=1\end{array}$ & $\begin{array}{l}\text { Case II: } \\
\qquad \begin{aligned} \frac{\partial Y(1,0)}{\partial I} & =-p \\
\frac{\partial Y(1,1)}{\partial I} & =1-p\end{aligned}\end{array}$ & $\begin{array}{l}\text { Case IV: } \\
\qquad \begin{aligned} \frac{\partial Y(1,0)}{\partial I} & =1-2 p \\
\frac{\partial Y(1,1)}{\partial I} & =2-2 p\end{aligned}\end{array}$ \\
\hline
\end{tabular}

Note that we distinguish these four cases because the periods covered by insurance as well as the shock realization in period 1 are known (also in our dataset) when deciding about child labor and consumption in the first period. In each case the household faces the risk of a good ( $\left.\theta_{2}=0\right)$ or bad $\left(\theta_{2}=1\right)$ state in period 2. Condition (8) and the corresponding function $f$ reflect this risk by weighting the two states with subjective probabilities.

The function $f$ changes with $I$ because $I$ will change the overall potential budget in different states. Households consequently need to adjust the budget split via $Y_{1}$ to preserve the optimality condition $f=0$, see equation (8), in the following way:

$$
\frac{\partial f}{\partial I} d I+\frac{\partial f}{\partial Y_{1}} d Y_{1}=0
$$

which implies

$$
\frac{d Y_{1}}{d I}=-\frac{\partial f / \partial I}{\partial f / \partial Y_{1}}
$$


If we are able to determine the signs of $\partial f / \partial I$ and $\partial f / \partial Y_{1}$, we know the sign of $d Y_{1} / d I$. We therefore examine each partial derivative in turn:

$$
\frac{\partial f}{\partial Y_{1}}=\left(-\frac{1}{Y_{1}^{2}}-\frac{\sigma p_{\theta}}{\left(Y\left(\theta_{1}, 1\right)-Y_{1}\right)^{2}}-\frac{\sigma\left(1-p_{\theta}\right)}{\left(Y\left(\theta_{1}, 0\right)-Y_{1}\right)^{2}}\right)(1+\gamma)<0,
$$

i.e. this derivative is always negative, as we had already discussed earlier, where we argued that $f$ is strictly decreasing in $Y_{1}$. Inserting this result in (11), we obtain that

$$
\operatorname{sign}\left(\frac{d Y_{1}}{d I}\right)=\operatorname{sign}\left(\frac{\partial f}{\partial I}\right)
$$

at the optimal choices. If $\partial f / \partial I>0$ introducing (more) insurance would lead to an increase in the period one budget $Y_{1}$ and consequently to a decrease in period 1 child labor. We therefore need to consider $\partial f / \partial I$.

$$
\begin{aligned}
\frac{\partial f}{\partial I}=\frac{\partial f}{\partial Y\left(\theta_{1}, 1\right)} & \frac{\partial Y\left(\theta_{1}, 1\right)}{\partial I}+\frac{\partial f}{\partial Y\left(\theta_{1}, 0\right)} \frac{\partial Y\left(\theta_{1}, 0\right)}{\partial I} \\
& =\frac{(1+\gamma) \sigma p_{\theta}}{\left(Y\left(\theta_{1}, 1\right)-Y_{1}\right)^{2}} \frac{\partial Y\left(\theta_{1}, 1\right)}{\partial I}+\frac{(1+\gamma) \sigma\left(1-p_{\theta}\right)}{\left(Y\left(\theta_{1}, 0\right)-Y_{1}\right)^{2}} \frac{\partial Y\left(\theta_{1}, 0\right)}{\partial I}
\end{aligned}
$$

The sign of $\partial f / \partial I$ depends on the shock realizations and on the number of periods insurance was bought for (see Table C1). In the following we will distinguish all four cases shown in the table. We start with cases I and II (insurance in period two only) because this reflects the pure risk reduction effect of insurance (i.e. the ex-ante effect) without a budget effect on average. In contrast, cases III and IV will always involve a premium payment with or without insurance benefit, i.e. including the ex-post effect. This positive or negative budget effect makes it more complicated to interpret the insurance effect.

Case I: $\quad$ Insurance bought for period 2 only and no shock in period 1

Inserting the respective derivatives of Table $\mathrm{C} 1$ in equation (12) we obtain

$$
\frac{\partial f}{\partial I}=\frac{\sigma p_{\theta}(1+\gamma)(1-p)}{\left(Y\left(\theta_{1}, 1\right)-Y_{1}\right)^{2}}-\frac{\sigma\left(1-p_{\theta}\right)(1+\gamma) p}{\left(Y\left(\theta_{1}, 0\right)-Y_{1}\right)^{2}}
$$

which is positive if

$$
p_{\theta}(1-p)\left(Y\left(\theta_{1}, 0\right)-Y_{1}\right)^{2}>p\left(1-p_{\theta}\right)\left(Y\left(\theta_{1}, 1\right)-Y_{1}\right)^{2} .
$$


Noting that $Y\left(\theta_{1}, 0\right)=Y\left(\theta_{1}, 1\right)+S$ we can re-write condition (13) as

$$
p_{\theta}(1-p)\left(Y\left(\theta_{1}, 1\right)-Y_{1}+S\right)^{2}>p\left(1-p_{\theta}\right)\left(Y\left(\theta_{1}, 1\right)-Y_{1}\right)^{2} .
$$

This condition is satisfied if $p_{\theta} \geq p$, i.e. if households are not underestimating the probability of a health shock. The reason is that the total potential budget with a shock in period 2 is lower than without, i.e. $Y\left(\theta_{1}, 0\right)>Y\left(\theta_{1}, 1\right)$. Therefore child labor decreases in period 1 if households buy insurance for period 2. Condition (13) is also satisfied if households underestimate the shock probability, as long as they do not underestimate it too much.

\section{Case II: $\quad$ Insurance bought for period 2 only and shock in period 1}

The condition to be fulfilled is equivalent to Case I. Hence, irrespective of the shock drawn in period 1 households will increase period 1 budget (i.e. reduce precautionary saving) if they buy insurance for period 2. As a consequence, child labor decreases in period 1 (ex-ante effect).

Case III: $\quad$ Insurance bought for both periods and no shock in period 1

Inserting the respective derivatives of Table $\mathrm{C} 1$ in equation (12) we obtain

$$
\frac{\partial f}{\partial I}=\frac{\sigma p_{\theta}(1+\gamma)(1-2 p)}{\left(Y(0,1)-Y_{1}\right)^{2}}-\frac{\sigma\left(1-p_{\theta}\right)(1+\gamma) 2 p}{\left(Y(0,0)-Y_{1}\right)^{2}}
$$

which is positive if

$$
p_{\theta}(1-2 p)\left(Y(0,0)-Y_{1}\right)^{2}>2 p\left(1-p_{\theta}\right)\left(Y(0,1)-Y_{1}\right)^{2}
$$

There are two ways to fulfill this condition. First, if households overweight the shock probability by at least factor two ( $\left.p_{\theta} \geq 2 p\right)$, the condition (14) will be fulfilled for any overall budget. Second, even without overweighting loss probabilities, the condition will hold for sufficiently poor households. This is because in case of a shock they will have to restrict their second period budget, i.e. $Y(0,1)-Y$, to such low levels that the condition (14) holds because

$$
\frac{Y(0,1)-Y_{1}}{Y(0,0)-Y_{1}}<<1 \text { and consequently } \frac{\left(Y(0,1)-Y_{1}\right)^{2}}{\left(Y(0,0)-Y_{1}\right)^{2}}<\frac{p_{\theta}(1-2 p)}{2 p\left(1-p_{\theta}\right)}
$$




\section{Case IV: $\quad$ Insurance bought for both periods and shock in period 1}

Inserting the respective derivatives of Table $\mathrm{C} 1$ in equation (12) we obtain

$$
\frac{\partial f}{\partial I}=\frac{\sigma p_{\theta}(1+\gamma)(2-2 p)}{\left(Y(1,1)-Y_{1}\right)^{2}}+\frac{\sigma\left(1-p_{\theta}\right)(1+\gamma)(1-2 p)}{\left(Y(1,0)-Y_{1}\right)^{2}}
$$

which is positive if

$$
p_{\theta}(2-2 p)\left(Y(1,0)-Y_{1}\right)^{2}>(2 p-1)\left(1-p_{\theta}\right)(\underbrace{Y(1,1)-Y_{1}}_{<Y(1,0)-Y_{1}})^{2}
$$

Condition (15) is fulfilled under mild conditions. It will hold under the same conditions as in Case I and II (no underweighting of probabilities). Even if households were underweighting, the condition would hold as long as the objective shock probability $p$ is not larger than 0.5 , as the right hand side would become negative while the left hand side remains positive.

Even if a shock occurs with very large probability $p>0.5$, households must be severely underweighting probabilities before condition (15) is violated. Consider the worst case where $S$ is very small relative to the budget such that $\left(Y(1,0)-Y_{1}\right)^{2}$ is hardly larger than $\left(Y(1,1)-Y_{1}\right)^{2}$. Even then condition (15) is satisfied as long as $p_{\theta}>2 p-1$.

Suppose a shock occurs with probability $p=0.5+\varepsilon$, condition (15) is satisfied if

$$
p_{\theta}>2 \varepsilon .
$$

This would only not be satisfied if households were extremely underestimating the probability of a shock. Condition (15) is even more likely to be fulfilled if the size of the shock $S$ becomes larger relative to the budget.

The reason why (15) is likely to be fulfilled is that together with the substitution effect of budget from period 2 to period 1 through decreased risk there is a positive overall budget effect of the insurance because one shock is already paid, i.e. the ex-post effect of the payout in period 1 amplifies the ex-ante effect of having period 2 insured. Therefore child labor decreases in period 1 if households buy insurance.

Summing up, reducing risk in the future while keeping average overall budget constant decreases child labor already today (Cases I and II). This is because households need to worry less about creating precautionary savings. This effect becomes more pronounced if households are poorer and if they overweight the shock probability. If they are sufficiently poor or overweighting enough, even buying insurance in both periods and not profiting at 
present (negative budget effect, Case III), will reduce child labor. Note that we are not considering corner solutions here. From a certain income level onwards child labor is always zero and cannot be reduced further.

\section{Appendix D - Data Structure}

Table D1 provides the names and number of observations for the 9 treatment and 4 control branches. The number of households interviewed varies from 96 to 258 .

Table D1: Observations per branch at baseline

\begin{tabular}{l|ccc}
\hline \multicolumn{1}{c|}{ Branch Name } & Treatment? & Households & Individuals \\
\hline Garhi Khata & YES & 138 & 841 \\
Gulshan e Hali & No & 258 & 1,512 \\
Hussainabad & YES & 96 & 587 \\
Islamabad & YES & 153 & 908 \\
Islamia Colony & No & 192 & 1,145 \\
Kotri-1 & YES & 198 & 1,218 \\
Kotri-2 & No & 141 & 874 \\
Latifabad-12 & No & 186 & 1,222 \\
Latifabad-5 & YES & 147 & 897 \\
Liaqat Colony & YES & 120 & 723 \\
Pathan Colony & YES & 204 & 1,322 \\
Phuleli & YES & 105 & 564 \\
Pretabad & YES & 159 & 1,122 \\
\hline \multicolumn{1}{c}{ All } & \multicolumn{3}{c}{2,097} \\
\hline \hline
\end{tabular}




\section{Appendix E - Description of Insurance Package}

This appendix provides details on the insurance package provided by NRSP. (This information is taken from NRSP's innovation proposal with the ILO Microfinance for Decent Work Program.) The innovation in the treatment branches consisted in offering insurance also to other adult members of the household (in addition to the client, the spouse and their minor children who are mandatorily insured). In addition, clients in treatment branches were frequently visited by staff members to help with filing claims.

Coverage for Hospitalization

\begin{tabular}{|l|c|}
\hline Insured & $\begin{array}{c}\text { Self }+ \text { Spouse }+ \text { minor children }+ \text { Adults } 18 \text { or } \\
\text { above years }\end{array}$ \\
\hline Age & 18 or above \\
\hline Hospitalization Confinement & Min 24 Hours \\
\hline Sum Insured for Hospitalization & Rs. $15,000 /$ - for each family member \\
\hline Premium Per family per annum & Rs. PKR 100 per adult/- \\
\hline
\end{tabular}

Benefits for Hospitalization

- Hospital Room charges

- Miscellaneous hospital services and services such as

- Physicians or surgeons visits

- Prescription drugs

- Prescribed Pathological and Radiological investigations

- Prescribed ECGs,ETT,ECHO,Angiography,M.R.I., C.T.Scan, Ultrasound or any other diagnostics test required

- Blood Transfusion

- Operation theater Charges

- Anesthetist's Fees

- Stitching Material

- Physiotherapy

- Radiotherapy and Chemotherapy

- Instruments required in the treatment

- Cutting operations

- *Pregnancy(sub limit 7500/-)

- Pregnancy complications

- Reasonable transportation cost of insured

- Direct Settlement Facility by NRSP offices to panel hospital

* Pregnancy claim should arise after seven to nine month of date of enrolment

\section{Exclusions}

- OPD Cases

- Injuries as a result of illegal Act

- Treatment in any sanatorium, nursing home or long term care facility that is not a hospital

- Expenses directly or indirectly resulting from birth defects, congenital defects/illness and deformities of any nature

- Experimental or unproven treatment 
- Dental examinations, X-ray, extraction, and orthodontic treatment or oral surgery except as a result of accidental injury

- Pre existing diseases

- Routine medical examinations, routine eye or ear checkup, Vaccination, Contact lenses, hearing aids and examination for travel or employment

- Donor for organ transplant claims

- Air ambulance expenses

- Cost of limbs or supporting equipment for revival or correction of the function's of body

- Cost of medicines for cosmetic treatment and or treatment of falling hair or hair implant cosmetic/ Plastic surgery

Personal Accident Insurance

(Only for the Earning Members of the Family / Head of Household)

\section{Benefits for Personal Accidents}

- Death

$100 \%$

- Permanent Disability of both eyes $100 \%$

- Permanent Disability of one eye and one limb $75 \%$

- Permanent Disability of one eye or one limb $50 \%$

- Permanent Disability of one finger or thumb or toe $10 \%$

If at any time during any period of insurance, the Insured Persons shall sustain any bodily injury caused by accidental external and visible means which injury shall solely and independently of any other cause result in his death or permanent total disability, the Company will pay to the Insured Persons or in the event of his death, to his immediate Dependants, the compensation stated in the Schedule.

Provided always that:

1. Death or permanent disability (as mentioned in the Schedule of Compensation) takes place within three Calendar months of the occurrence of the injury.

a) Compensation shall not be payable under more than one of the items of the Schedule of compensation in respect of consequences of the same accident.

2. The total sum payable under Personal Accident of Policy in respect of any one or more claims shall not exceed in all, in any one period of insurance, the Sum Insured.

Death or permanent disability (as mentioned in the Schedule of Compensation) shall only be payable for the Earning Member of a Family and not to the rest of the Family Members. In case of Death, the Compensation shall be payable to the immediate Dependants only.

\section{Exclusions for Accident Insurance}

1. This policy does not cover death or bodily injury due to or resulting from:

1. Intentional self injury, suicide or attempted suicide

2. War, invasion, act of foreign enemy, hostilities, whether war will be declared or not, civil war, mutiny, rebellion, revolution, insurrection, strike, riot, civil commotion, military or usurped power.

3. The insured being under the influence of, or being affected by intoxicating liquor or drug or drugs, venereal disease

4. The insured engaging in flying or air travel of any kind (other than as a passenger in any fully licensed passenger carrying aircraft and/or helicopter but not as a member of the crew and not for purpose of undertaking any trade or technical operation therein), polo, steeple chasing, professional football, mountaineering necessitating the use of ropes or guides, winter sports, riding or driving in any kind of race speed or during test or practice thereof, or occupational use of power driven woodworking machinery. 
Funeral expense coverage is only for client who availed loan facility.

\section{Claim Settlement Procedure}

i) The Insured shall contact the NRSP field officer for hospitalization, who will guide the patient to nearest Government and/or Armed forces hospitals and/or recognized private hospital, except in case of emergency, wherein at a later date NRSP officer shall be informed.

ii) The Insured on discharge from hospital shall pay all medical bills and/or charges and then submit the claim to NRSP field Officer for reimbursement.

iii) The claim shall be verified and subsequently be sent by NRSP fortnightly from date of receipt from Insured Person to the Company along with following documents;
a) Filled-in claim form
b) Hospital discharge report
c) Original hospital bills
d) Laboratory reports (Copies)
e) Medicine Invoices along with doctor's prescription
f) Copy of Premium Receipt
g) Copy of Insured's National Identity Card
h) Other supporting documents

The Company shall process the claim and send the cheque in the name of NRSP within 15 days, provided all documents are in order.

i) The injured Insured/immediate Dependants shall contact the NRSP for compensation.

ii) The NRSP field staff shall guide the Insured/ immediate Dependants to submit the claim along with the following documents within Seven days of incident.

a) Death Certificate verified

b) Police Report / Roznamcha

c) Doctor's report on disability / death

d) Copy of National Identity Card of Assured ('Form-B' in case of young children)

e) Copy of National Identity Card of immediate Dependants in case of Death.

f) Copy of Premium Receipt

iii) The Field staff shall forward the attested copies of all the above documents, except Police Report (required in original) within Seven days of receipt from Insured Person to the Company, which shall process the claim.

iv) Cheque shall be sent in the name of NRSP within 15 days, provided all documents are in order. 